\title{
The Influence, Barriers to and Facilitators of Anterior Cruciate Ligament Rehabilitation Adherence and Participation: a Scoping Review
}

\author{
Adam Walker ${ }^{1,2^{*}}$ D, Wayne Hing ${ }^{1}$ and Anna Lorimer $^{1}$
}

\begin{abstract}
Background: Outcomes following anterior cruciate ligament $(A C L)$ reconstruction are considered poor. There are many factors which may influence patient outcomes. As such, the purpose of this review was to report on the influence, barriers to and facilitators of rehabilitation adherence and participation after ACL reconstruction, providing information to help clinicians and patients make quality decisions to facilitate successful rehabilitation.

Methods: A systematic search of five electronic databases was undertaken in identifying studies from inception to 18 July 2019. The search included English language articles reporting on the influence, barriers to and facilitators of adherence and participation in rehabilitation of patients who have undergone ACL reconstruction. Data extraction and synthesis of included studies were undertaken.

Results: Full text articles ( $n=180$ ) were assessed for eligibility following screening of titles and abstracts ( $n=1967)$, yielding 71 studies for inclusion. Forty-four articles investigated 'rehabilitation prescription and participation' and 36 articles investigated 'rehabilitation barriers and facilitators'. The results indicate that a moderately or minimally supervised rehabilitation program is at least as effective as a fully supervised high-frequency rehabilitation program, although a longer duration of supervised rehabilitation is associated with improvement in a multitude of functional outcomes. A number of psychological factors associated with rehabilitation adherence were also identified. The most commonly investigated concepts were self-motivation, athletic identity and social support. Patients perceived the therapeutic relationship, interaction with family and friends, self-motivation, fear of reinjury, organisation/lack of time and interpersonal comparison as the most common barriers to and facilitators of rehabilitation.

Conclusions: A longer duration of supervised rehabilitation is associated with an increased chance of meeting functional and return to sport criteria; however, the optimal supervised rehabilitation frequency is yet to be determined. Identification of the barriers to and facilitators of adherence and participation in ACL rehabilitation provides an opportunity for further research to be conducted to address personal, environmental and treatmentrelated factors, with the aim to improve rehabilitation outcomes.
\end{abstract}

Keywords: Anterior cruciate ligament, Physiotherapy, Return to sport, Adherence, Compliance, Rehabilitation

\footnotetext{
* Correspondence: adam.walker@student.bond.edu.au

${ }^{1}$ Faculty of Health Sciences and Medicine, Bond University, Gold Coast 4226, Australia

${ }^{2}$ Bond Institute of Health and Sport, Promethean Way, Robina, QLD 4226, Australia
} 


\section{Key Points}

- A longer duration of supervised rehabilitation is associated with more favourable post-operative outcomes.

- The optimal frequency of supervised post-operative rehabilitation is unknown.

- Patients experience a variety of psychological, environmental, personal and treatment-related barriers to and facilitators of rehabilitation.

\section{Background}

Anterior cruciate ligament (ACL) injury occurs during rapid valgus loading and internal tibial rotation of the knee [1]. Every year, 3\% of amateur athletes injure their ACL, often requiring subsequent reconstruction [2]. Injury of the ACL is also one of the most devastating, resulting in significant time loss from sport [2], longterm functional knee impairments [3], reduced quality of life [4], financial burden [5] and early-onset osteoarthritis [6].

Despite significant advances in surgical technique, the outcomes following ACL reconstruction continue to be reported as poor [7]. Research demonstrates that only $55 \%$ of patients who undergo ACL reconstruction make a return to competitive sport [8], and between 15 and $23 \%$ of young athletes will suffer a re-rupture or injure the contralateral knee [9]. Reinjury rates are even higher for those under 18 at 33\% [10].

Potentially, the underutilisation of rehabilitation in recovery from ACL injury is contributing to the poor outcomes [11]. Growing evidence suggests that due to inadequacies in current rehabilitation programs, patients return to sport (RTS) too early and with significant deficits in knee function, risking reinjury and long-term impairments [12]. There has been substantial research attempting to formulate an evidence base of what best practice ACL rehabilitation programs should include [13]. Despite this, Van Melick et al. (2016) highlighted the current lack of evidence regarding the optimal rehabilitation period or how many appointments work best for RTS [14]. Furthermore, it appears warranted to consider the contextual and personal factors of rehabilitation programs that may act as barriers to or facilitators of rehabilitation. Increased awareness and understanding of these factors may offer new insights and opportunities to improve long-term ACL reconstruction outcomes and enhance clinicians' ability to provide patient-centred care [15].

Clinicians are therefore continuing to seek guidance on the best way to structure and deliver rehabilitation to facilitate return to sport and minimise the risk of reinjury. With that in mind, this scoping review aims:
- To report on the influence of rehabilitation adherence and participation on outcomes after ACL reconstruction

- To report on the barriers to and facilitators of adherence and participation in ACL rehabilitation

- To provide information to help clinicians and patients make quality decisions to facilitate adherence and appropriate participation in ACL rehabilitation

\section{Methods}

A scoping review was conducted to synthesise evidence on ACL reconstruction rehabilitation adherence and participation for the clinician providing rehabilitation services to patients who have undergone ACL reconstruction. Due to the broad exploratory nature of the topic, a scoping review design and methodology was used to facilitate collation and mapping of evidence for the identification of key concepts, knowledge gaps and the types of evidence currently available [16].

\section{Research Questions}

The research questions are:

1. What is the reported influence of adherence and participation in ACL reconstruction rehabilitation on patient outcomes?

2. Which factors are reported to influence adherence and participation in ACL reconstruction rehabilitation?

\section{Protocol}

A single researcher (AW) conducted the literature search to identify, screen and select studies to be included in accordance with the Preferred Reporting Items for Systematic Reviews and Meta-Analysis Extension for Scoping Reviews (PRISMA-ScR) [17]. An a priori protocol was developed and published on the Open Science Framework (https://osf.io/a7tz8/ ?view_only=9bc5d21c0c034f70a37202abab7330c0) prior to data extraction, on the 10 August 2019. No changes were made to the protocol from publication through to completion.

\section{Study Design}

The search strategy was developed through the application of the methodological frameworks proposed by Arksey and O'Malley (2005) [16] and Peters et al. (2015) [18]. We followed a 3-step approach:

1. A pilot search of PubMed and Embase using the medical subject headings 'anterior cruciate ligament' AND reconstruction AND rehabilitation AND 'patient compliance' (May 2019). 
2. Identified keywords and terms relating to anterior cruciate ligament reconstruction rehabilitation adherence and participation (May 2019).

3. Execution of the final search strategy and further searching of reference lists of the selected articles, systematic reviews and narrative reviews (July 2019).

A search was formulated (supplementary file 1) and conducted in 5 databases (PubMed, Embase, CINAHL, SPORTDiscus and Web of Science) from inception to 18 July 2019. Articles were downloaded to the EndNote reference management software (https://www.endnote. $\mathrm{com} /$ ) for selection by AW according to the PRISMAScR statement [17] (Fig. 1).

\section{Eligibility criteria}

The eligibility criteria were defined by the Population (any individual that had undergone an anterior cruciate ligament reconstruction regardless of graft type or concomitant injury), Concept (any study reporting on the effect of adherence and participation in rehabilitation or a rehabilitation program) and Context (all periods of time, outcomes, comparators, follow up, rehabilitation setting and duration and type of intervention). The following types of publications were eligible for inclusion: original research, reviews, scoping reviews, systematic reviews, meta-analysis, case series and clinical commentaries.

Exclusion criteria were (a) non-English language, (b) examined pre-operative interventions or non-operative rehabilitation intervention for ACL rupture and (c) no access to the full text. The following were also excluded from our review: conference abstracts/proceedings, opinion pieces, guidelines, magazine and newspaper articles and rehabilitation protocols.

\section{Data extraction}

AW extracted data from publications meeting inclusion criteria into a custom Excel spreadsheet. Data extraction, categorisation and mapping were performed as per Peters et al. (2015) in an iterative process as the reviewer became more familiar with the evidence [18].

\section{Synthesis and risk of bias}

To answer the research questions, data were narratively synthesised by the author-defined categories: (A) rehabilitation prescription and participation and (B) barriers to and facilitators of rehabilitation. Studies in category A were further categorised into 3 subcategories: 'supervised rehabilitation frequency', 'supervised rehabilitation duration' and 'rehabilitation adherence'. Studies in category B were further categorised into three sub-categories: 'psychological', 'patient

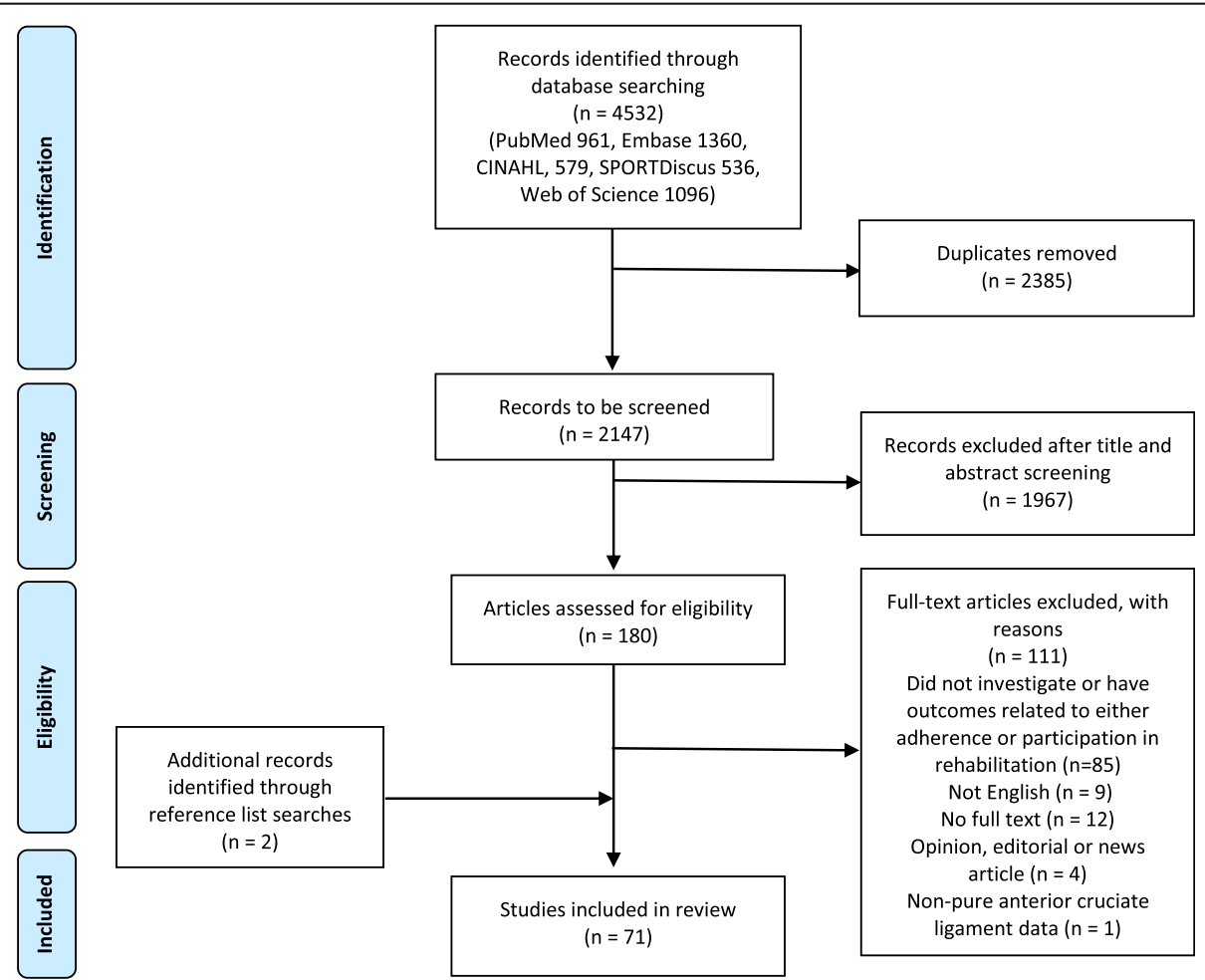

Fig. 1 Preferred Reporting Items for Systematic Reviews and Meta-Analysis Extension for Scoping Reviews (PRISMA-SCR) flow diagram 
perspectives' and 'other factors'. Studies may be allocated to multiple groups. Results were mapped based on the population profile (age, sex, activity level), study design and concepts investigated. The synthesis of qualitative data was guided by the methodological framework presented by Thomas and Harden (2008) [19]. In line with the recommended scoping review methodology, a quality appraisal is not required $[16,18]$.

\section{Results}

The search strategy yielded 4532 citations with two additional records added following reference list searching $[20,21]$. Duplicates $(n=2385)$ were removed, and exclusion based on screening of title and abstract $(n=1967)$ left 180 full-text articles which were retrieved and assessed for eligibility. Of these, 111 were excluded for the following reasons: 85 studies did not investigate or have outcomes related to either adherence or participation in rehabilitation; nine were of non-English language; 12 had no access to full text; four were opinion, editorial or news articles; and one article with a non-pure ACL data set (participants from multiple injuries). Seventyone publications fulfilled the criteria and were included in the review (Fig. 1).

The 71 included articles included 19 reviews and 52 studies. The articles were categorised as per Table 1, with four reviews [13, 58-60] and five studies [30, 61, $62,70,71]$ classified in multiple categories. As outlined in the synthesis and risk of bias methods section, the articles in category (A) were selected to answer the first research question: What is the reported influence of adherence and participation in ACL reconstruction rehabilitation on patient outcomes? Forty-four articles consisting of 12 reviews and 32 original studies were included in this category. An article was categorised into 'supervised rehabilitation frequency' if it investigated the difference in outcomes between varying rates of attendance to a rehabilitation service. Most of these articles were developed to investigate home versus clinic-based rehabilitation. An article was categorised as 'supervised rehabilitation duration' if it investigated the association between a shorter versus longer duration of supervised rehabilitation on outcome and an article was categorised as 'rehabilitation adherence' if it utilised an adherence measure to determine the correlation between adherence to a prescribed rehabilitation protocol and outcome.

The articles in category (B) were selected to answer the second research question: Which factors are reported to influence adherence and participation in ACL reconstruction rehabilitation? Thirty-six articles consisting of 10 reviews and 26 original studies were included in this category. An article was categorised into 'psychological' if it investigated the association between a psychological variable and adherence to rehabilitation, as 'patient perspectives' if the study included a qualitative research methodology reporting on patients' opinions and perspectives on barriers to and facilitators of rehabilitation and as 'other factors' if it did not fit the first two categories.

Publication dates varied from 1997 to 2019. The number of articles published increased substantially from 2015 (Fig. 2), illustrating the rise in interest in the topic.

\section{Category (A) Rehabilitation Prescription and Participation \\ Supervised Rehabilitation Frequency \\ Reviews}

All nine included reviews investigated home versus clinic-based or supervised rehabilitation (Table 2). Conclusions were consistent across the reviews. All systematic reviews either stated that home-based rehabilitation is as equally effective as clinic-based rehabilitation, or the evidence was inconclusive. The methodological quality assessments in each review consistently highlighted issues with the quality of the current available evidence. Anderson et al. (2016) performed the most recent review inclusive of evidence until 2014, raising questions about the currency of the evidence presented [13].

\section{Original Studies}

Of the 20 included original studies regarding supervised rehabilitation frequency, eight studies were retrospective

Table 1 Number of articles included in each category

\begin{tabular}{lllll}
\hline & Reviews & References & Original studies & References \\
\hline Category (A) Rehabilitation prescription and participation & & & 20 & {$[30-49]$} \\
Supervised rehabilitation frequency & 9 & {$[13,22-29]$} & 8 & {$[50-57]$} \\
Supervised rehabilitation duration & 0 & & 4 & {$[61-64]$} \\
Rehabilitation adherence & 3 & {$[58-60]$} & & 8 \\
Category (B) Rehabilitation barriers and facilitators & 10 & {$[13,21,58-60,65-69]$} & 15 & {$[62,70-76]$} \\
Psychological & 0 & & 3 & {$[15,20,30,61,71,77-86]$} \\
Patient perspectives & 0 & & {$[30,70,87]$} \\
Other factors & & &
\end{tabular}

Bold text highlights the two main categories 


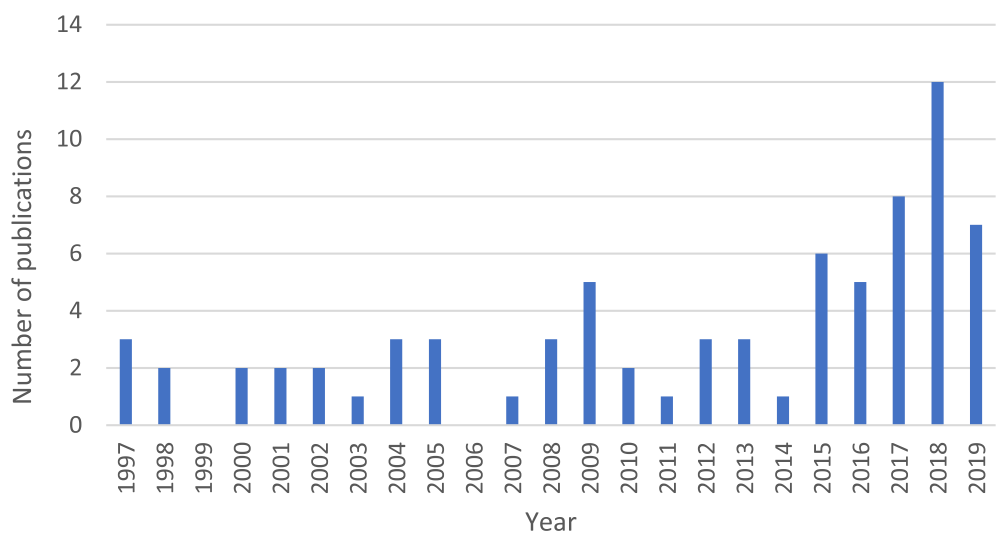

Fig. 2 Number of academic publications by year meeting selection criteria

in design, seven randomised controlled trials (RCT), three prospective, one cross-sectional and one case report (Table 3). The mean age was $27.6(21.4-35.5)$. All but one study had male and female participants. Thirteen studies utilised the bone-patella tendon-bone (BPTB) graft, ten hamstring graft, two allografts and one did not state. Participant activity level was not stated in 13 studies, while athletes of various levels were involved in seven studies.

A variety of outcome measures (OMs) were used (Table 3) with no single OM used consistently across the majority of studies. Outcome measure use was investigated by grouping the type of $\mathrm{OM}$ into the following categories: hop tests, isokinetic dynamometry, patient reported OMs, clinical-based OMs and other
OMs. The number of studies in each category were as follows; five studies used at least one hop test [30, 33, 36, 40, 46], eight studies used an isokinetic dynamometry strength measure $[30,31,34,37,38$, $40,42,45]$ and 18 different patient-reported OMs were utilised in 12 different studies [30, 32-39, 43, 44, 46]. Eighteen different clinical-based assessments (pain, range of motion, atrophy, effusion, laxity, Lysholm knee score, Tegner activity scale and international knee documentation committee knee evaluation) were used in 15 studies [31-38, 40, 43-48] and 14 other OMs (RTS status/activity level, re-rupture, gait analysis, functional movement screen, surgery satisfaction, imaging and demographics) were utilised in 10 studies [38, 39, 41-44, 46-49].

Table 2 Summary of included reviews investigating 'supervised rehabilitation frequency'

\begin{tabular}{|c|c|c|c|c|c|}
\hline Author (year) & Review type & Dates & Methodological quality & $\begin{array}{l}\text { No. included original } \\
\text { studies }\end{array}$ & Conclusion \\
\hline Anderson et al. (2016) [13] & Systematic & $2004-14$ & Not assessed & 4 & Inconclusive \\
\hline Andersson et al. (2009) [22] & Systematic & $\begin{array}{l}1995- \\
2009\end{array}$ & $\begin{array}{l}\text { Severely limited by methodology } \\
\text { quality }\end{array}$ & 7 & Inconclusive \\
\hline $\begin{array}{l}\text { Coppola and Collins (2009) } \\
\text { [23] }\end{array}$ & Systematic & $\begin{array}{l}1980- \\
2007\end{array}$ & Moderate quality & 3 & Inconclusive \\
\hline Kruse et al. (2012) [24] & Systematic & $2006-10$ & Large biases in studies & 6 & $\begin{array}{l}\text { Equally } \\
\text { effective }\end{array}$ \\
\hline Lobb et al. (2012) [29] & $\begin{array}{l}\text { Non- } \\
\text { systematic }\end{array}$ & $\begin{array}{l}\text { Until } \\
2011\end{array}$ & Moderate evidence & 2 & $\begin{array}{l}\text { Equally } \\
\text { effective }\end{array}$ \\
\hline Papalia et al. (2013) [25] & Systematic & $\begin{array}{l}\text { Until } \\
2013\end{array}$ & Good quality & 10 & $\begin{array}{l}\text { Equally } \\
\text { effective }\end{array}$ \\
\hline Risberg et al. (2004) [26] & Systematic & $\begin{array}{l}\text { Until } \\
2003\end{array}$ & Significant limitations across studies & 3 & $\begin{array}{l}\text { Equally } \\
\text { effective }\end{array}$ \\
\hline Trees et al. (2005) [27] & Systematic & $\begin{array}{l}\text { Until } \\
2005\end{array}$ & Poor & 3 & $\begin{array}{l}\text { Equally } \\
\text { effective }\end{array}$ \\
\hline Wright et al. (2008) [28] & Systematic & $\begin{array}{l}\text { Until } \\
2005\end{array}$ & Biases present & 4 & $\begin{array}{l}\text { Equally } \\
\text { effective }\end{array}$ \\
\hline
\end{tabular}

Methodological quality refers to the outcome of the quality appraisal undertaken by the review not the authors of this study. The conclusion stated is that of the included review in reference to the comparison of home versus clinic-based rehabilitation. The number of original studies is only those included in each review for the evaluation of home versus supervised rehabilitation 


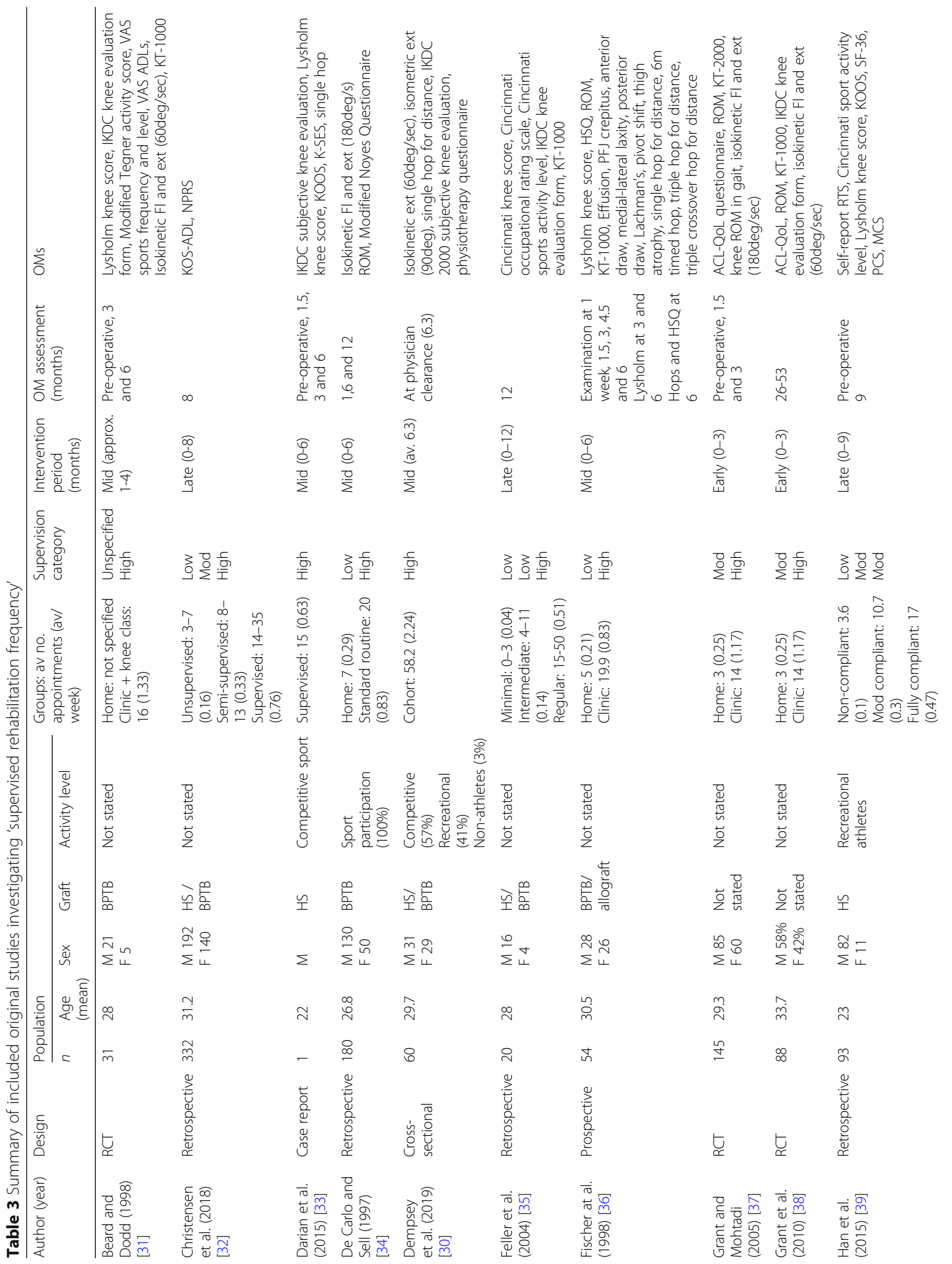




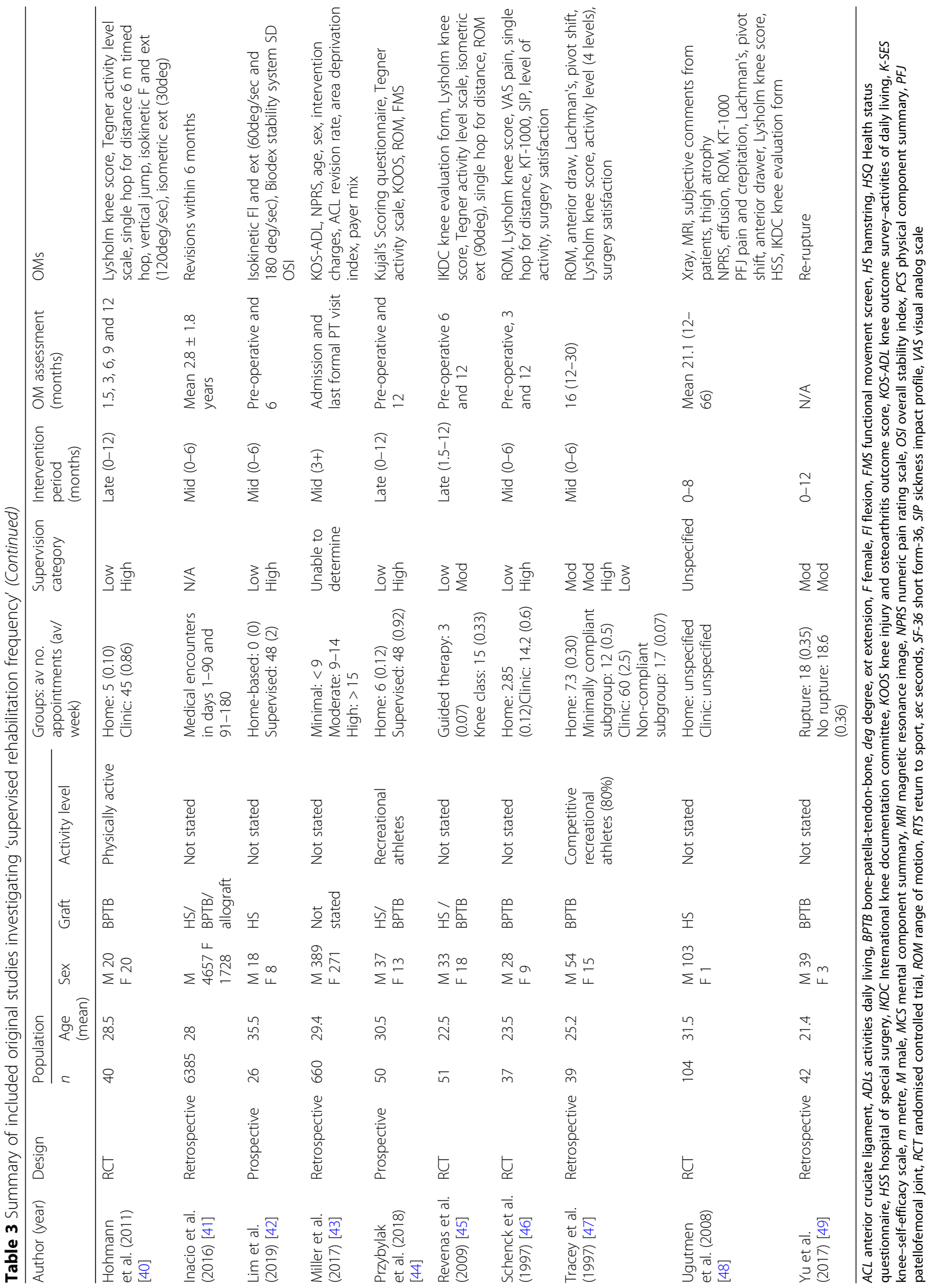


To determine the correlation between frequency of supervised rehabilitation and rehabilitation outcome, the frequency of appointments in each intervention group was mapped based on the average number of weekly appointments across the intervention period. Patients who attended less than once per month were classified as low, between 1 and $2 \times /$ month as moderate and more than twice per month as high across the duration of their rehabilitation.

The intervention period was labelled according to the stages of rehabilitation the intervention spanned; early-stage (0-3 months), mid-stage (0-6 months) and late-stage (0-6 months+). Eight studies investigated through to the late phase $[32,35,39,40,44$, $45,48,49]$, nine mid-stage [30, 31, 33, 36, 41-43, 46, $47]$ and two early-stage [37, 38]. Only five studies had a follow-up assessment period longer than the intervention period [31, 34, 37, 41, 47].

Thirteen of the included 20 studies showed no significant difference between low, moderate or high frequency supervised rehabilitation regardless of the intervention period. The non-significant studies were all seven RCTs [31, 37, 38, 40, 45, 46, 48], five retrospective studies [34, $35,41,47,49]$ and one prospective study [36]. Seven studies, all published in the last 4 years, showed an association between improved outcome and moderate or high-frequency supervised rehabilitation. Specifically, prospectively designed studies found associations between proprioception recovery [42], functional knee movement [42], higher return to preinjury level of sports [44] and better quality of life [44] in a highly supervised group than in a low supervision home-based group.

Studies utilising a retrospective methodology found an association between higher rehabilitation utilisation and significantly higher patient reported outcomes (Knee Outcomes Survey-Activities of Daily Living (KOS-ADL) scale [32, 43], Knee Injury and Osteoarthritis Outcome Score subscales [39], patient satisfaction [47] and numerical pain rating scale [43]), greater return to preoperative activities [39, 47] and improved Lysholm knee score $[39,47]$. Finally, in a cross-sectional study, Dempsey et al. (2019) found a weak positive correlation with isokinetic knee extension torque and level of supervision [30], while Darain et al. (2015) demonstrated a successful return to sport at 6 months with a high frequency of supervised rehabilitation in a case report [33].

\section{Summary}

Despite significant heterogeneity between the included studies and overall poor quality of research, it is reasonable to conclude that a moderately or minimally supervised rehabilitation program is at least as effective as a fully supervised high-frequency rehabilitation program. Recent publications, however, are showing an association between higher rehabilitation utilisation improving outcomes. It remains to be seen whether there is an optimal frequency of supervised rehabilitation visits and if this varies between stages of rehabilitation. From the current research, it is unclear whether participants met an acceptable level of function for return to sport and minimisation of reinjury.

\section{Supervised Rehabilitation Duration Original Studies}

Of the eight included original studies regarding supervision duration, seven studies are retrospective and one prospective in design (Table 4). The average age was 27.9 (26.2-29.7). Seven studies utilised a hamstring graft, while one study used both BРTB and hamstring graft. Participant activity level was reported in all but one study but was largely poorly defined. All studies compared a group of patients who completed a shorter duration of supervised rehabilitation (less than 3 or 6 months) to a group of patients who completed six or more months of rehabilitation, including structured agility, gym exercises, landing and on-field rehabilitation in line with current evidence-based recommendations

Supervised rehabilitation longer than 6 months was associated with improved outcomes at all assessment time points. Specifically, associations were found between longer supervised rehabilitation and functional symmetry [50, 51], a greater likelihood of meeting return to sport criteria and RTS at 12 months [50, 51], double leg vertical hop landing symmetry $[52,53]$, knee flexor rate of torque development and symmetry [54], speed and agility [55], knee extensor muscles torque parameters and LSI values [56] and better subjective outcomes [57]. Delaying the start of rehabilitation longer than one month after reconstruction was negatively associated with objective outcomes [57]. However, the duration of supervised rehabilitation was not associated with one leg vertical hop symmetry [53], knee joint stability, thigh and knee joint circumferences, active range of motion or everyday pain [55].

\section{Summary}

It is reasonable to conclude that a longer duration of supervised rehabilitation of at least 6 months, which includes structured agility, gym exercises, landing and onfield rehabilitation, is associated with more favourable outcomes after ACL reconstruction. It is likely that 9 or 12 months of structured supervised rehabilitation would offer further benefits. High-quality prospective randomised trials in this area are required.

\section{Adherence and outcome}

Reviews

All three reviews evaluated adherence to clinic and home-based rehabilitation against functional and 
Walker et al. Sports Medicine - Open

(2020) 6:32

Page 9 of 22

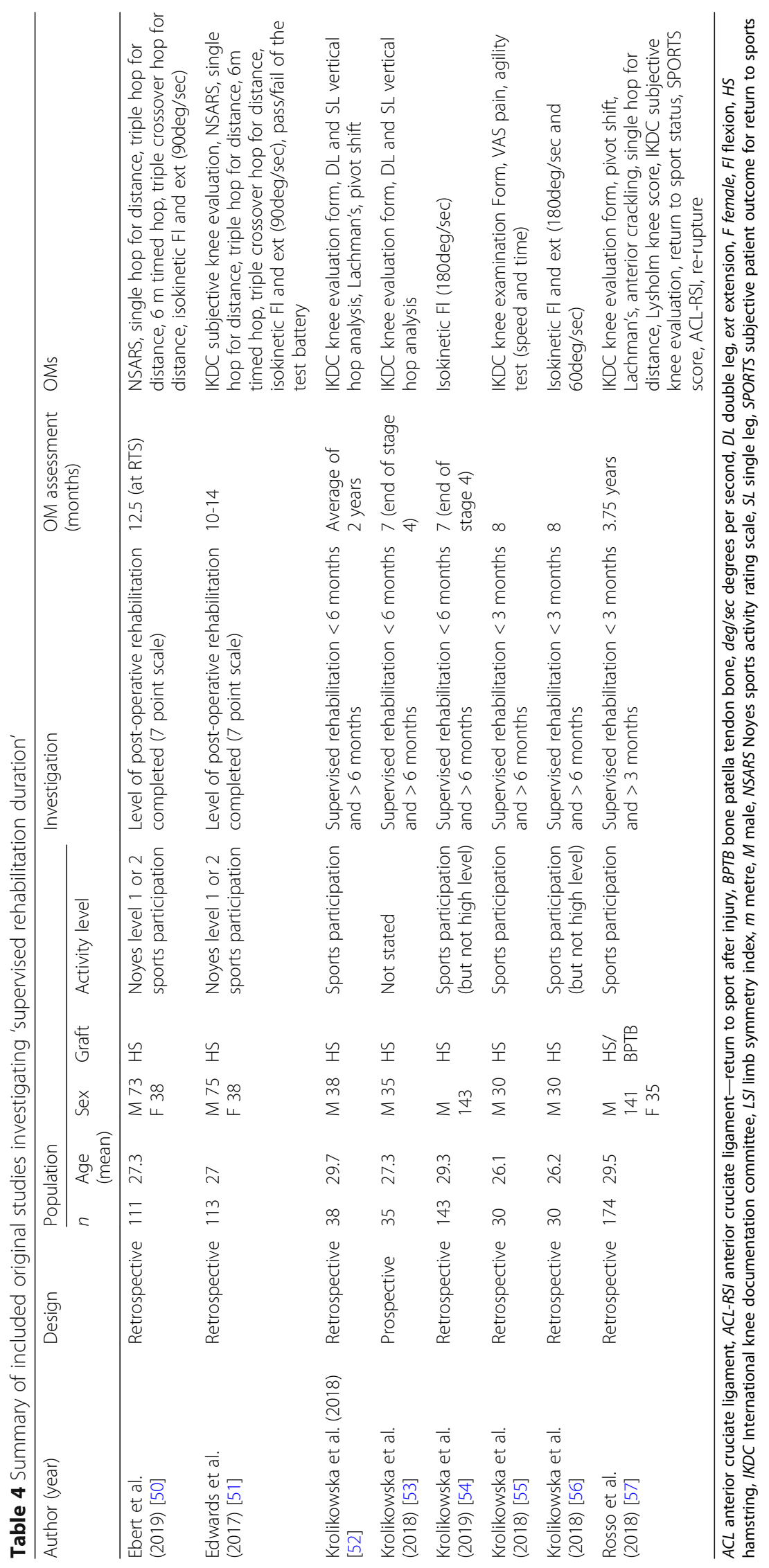


subjective outcomes (Table 5). There is an overall lack of evidence in the area of adherence and its effect on rehabilitation. Two reviews demonstrated a positive relationship between greater adherence to rehabilitation and improved outcomes $[58,60]$, while one review was inconclusive [59]. The methodological quality of included studies is uncertain as it has yet to be evaluated appropriately.

\section{Original studies}

Of the four included original studies regarding adherence, three studies of prospective design compared measures of adherence to clinic and home-based rehabilitation against functional and subjective outcomes over the first 6 weeks, 8 weeks and 6 months of rehabilitation (Table 6). The average age was 28.4 (26.9-29.4). One study used both BPTB and hamstring graft; the other two studies did not state. Participant activity level was stated in two studies. Outcomes were assessed at six months and 9-12 months.

It is inconclusive whether adherence has a positive effect on outcome. Significant correlations have been demonstrated between greater adherence to clinic-based rehabilitation and improved Knee Outcomes SurveySports Activities Scale scores [63] and one leg hop [62]. On the contrary, no significant correlation was found between any OMs and adherence measures in one study [64] and Brewer et al. (2004) found greater adherence to clinic-based rehabilitation was associated with high Lachman's grade [63]. Adherence to home-based rehabilitation negatively predicted Cincinnati Knee Rating System- Sport scores [64] and was a negative correlate to all OMs for participants $>30$ years, but a positive correlation if $<30$ years [64]. There was also no difference in any outcome measure with adherence to a web informational support system, despite the intervention group reporting being more committed to rehabilitation [61].

\section{Summary}

When considered with the results of the included reviews and the conflicting results of the few original studies investigating adherence to clinic and homebased rehabilitation against outcomes, an overall conclusion cannot be made on the effects of adherence to rehabilitation and outcome.

\section{Category (B) Rehabilitation Barriers and Facilitators \\ Psychological \\ Reviews}

The 10 reviews reported on 19 different psychological variables (Table 7). All of the variables could either act as a barrier or a facilitator to rehabilitation depending on the individual patient. For example, high selfmotivation is considered to facilitate rehabilitation, while low self-motivation may act as a significant barrier to rehabilitation.

The most to least commonly reported psychological variables were self-motivation [13, 21, 58, 59, 65, 68, 69], athletic identity $[13,58,59,65,68,69]$, self-efficacy [58, $60,65-68]$, self-confidence [13, 60, 65, 68, 69], positive self-talk [58-60, 65, 68], social support $[13,59,60,65$, $68]$, optimism $[13,65,68,69]$, goal setting $[59,60,65$, $68]$, stress [13, 21, 58, 65], fear of reinjury [58, 66, 68], locus of control [59, 69], age and sex differences in psychology [60, 69], self-esteem [58], pain tolerance [58], mood disturbance [58], situational stability [59], cognitive appraisal [66] and coping strategies [60], previous experiences [66] and attitudes [66]. As most of the reviews are narrative in nature and with a low overall evidence base ( 8 original studies), most of the conclusions within each review are theoretical in nature and were drawn from a wider evidence base from other injuries and disciplines. This provides scope for further research in this area in the ACL reconstruction population.

\section{Original Studies}

Of the eight included original studies regarding psychological factors, six studies were prospective in design, one retrospective and one case series (Table 8). The average age across the studies was 28.3 (25.2-32). All studies had male and female participants, and all but one study stated the participant activity level.

Twelve psychological concepts were investigated, utilising a variety of concept specific outcome measures to determine their correlation with adherence to clinic and home-based rehabilitation (Table 8). These were selfmotivation $[62,71,73,74]$, athletic identity $[62,73,75]$, social support $[62,71,73]$, stress and mood disturbance [75], neuroticism [75], pessimism [75], autonomy [74], personality traits [76], the theory of planned behaviour

Table 5 Summary of included reviews investigating 'adherence and outcome'

\begin{tabular}{llllll}
\hline Author (year) & Review type & Dates & Methodological quality & No. Included original studies & Conclusion \\
\hline Christino et al. (2015) [58] & Non-systematic & Not specified & Not assessed & N/A & Positive correlation \\
Mendonza et al. (2007) [59] & Systematic & Until 2006 & Not assessed & 3 & Inconclusive \\
te Wierike et al. (2013) [60] & Systematic & 2001-2011 & Good & 1 & Positive correlation
\end{tabular}

Methodological quality refers to the outcome or presence of a quality appraisal undertaken by the review not the authors of this study. The conclusion stated is that of the included review in reference to the correlation between adherence and rehabilitation outcome. The number of original studies is only those included in each review in the evaluation of adherence and outcome 
Walker et al. Sports Medicine - Open

(2020) 6:32

Page 11 of 22

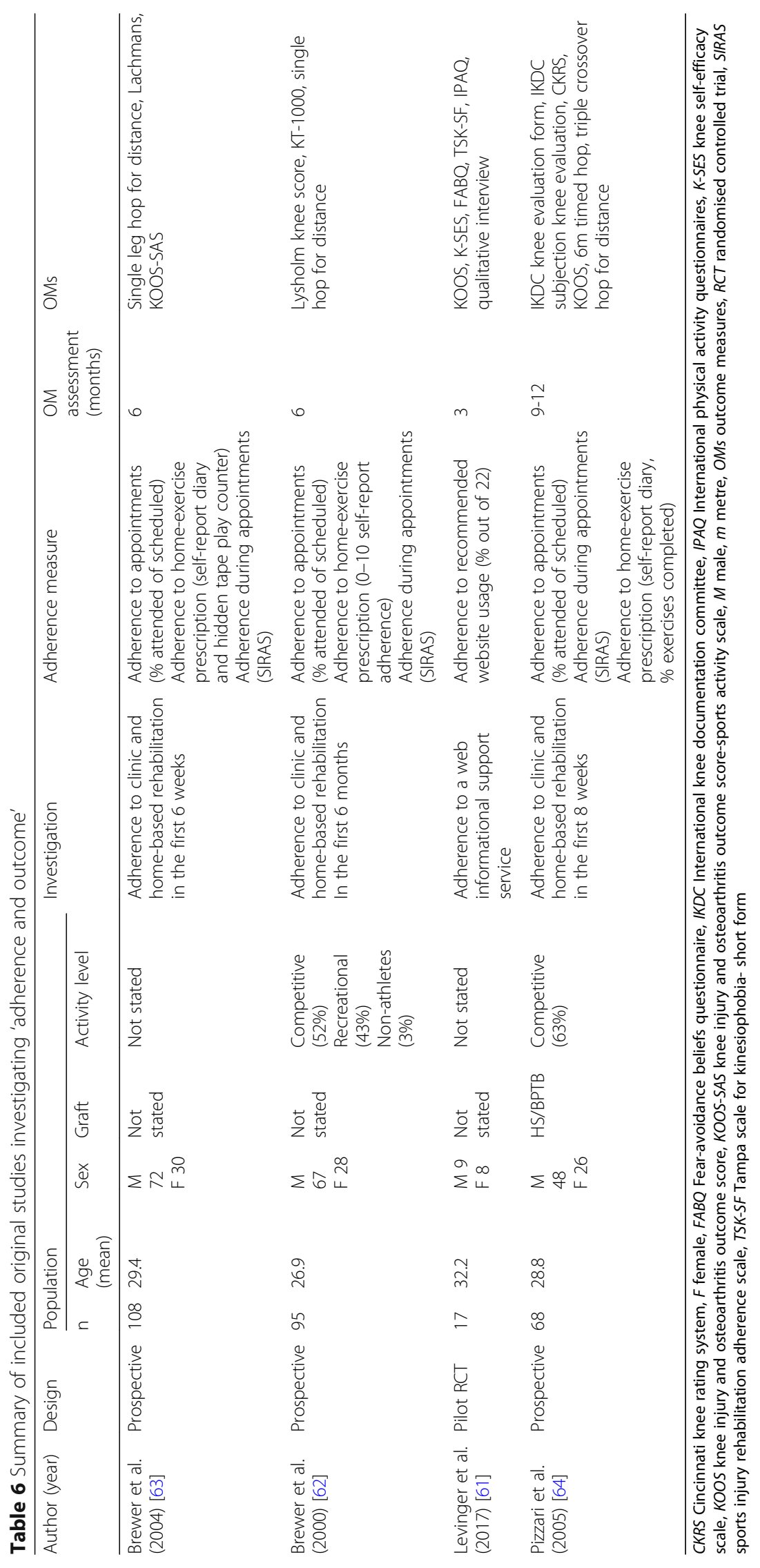


Table 7 Summary of included reviews investigating 'psychological'

\begin{tabular}{|c|c|c|c|c|c|}
\hline Author (year) & Design & Dates & $\begin{array}{l}\text { Methodological } \\
\text { quality }\end{array}$ & Included & Key concepts \\
\hline $\begin{array}{l}\text { Anderson et al. } \\
\text { (2016) [13] }\end{array}$ & Systematic & 2004-2014 & Not assessed & 2 & $\begin{array}{l}\text { Self-confidence, optimism, self-motivation, stress, } \\
\text { social support, athletic identity }\end{array}$ \\
\hline Ardern et al. (2016) [66] & Narrative & Not specified & Not assessed & $\mathrm{N} / \mathrm{A}$ & $\begin{array}{l}\text { Cognitive appraisal, previous experiences, attitudes, } \\
\text { self-efficacy, fear of reinjury }\end{array}$ \\
\hline $\begin{array}{l}\text { Burland et al. } \\
\text { (2019) [67] }\end{array}$ & Narrative & Not specified & Not assessed & N/A & Self-efficacy \\
\hline Christiano et al. (2015) [58] & Narrative & Not specified & Not assessed & 3 & $\begin{array}{l}\text { Self-esteem, post-traumatic stress, pain intolerance, } \\
\text { mood disturbance, goal setting, positive self-talk, fear } \\
\text { of reinjury, self-efficacy, self-motivation, athletic identity }\end{array}$ \\
\hline Everhart et al. (2015) [65] & Systematic & $1975-2012$ & $\begin{array}{l}63 / 90 \text { modified } \\
\text { Coleman score }\end{array}$ & 8 & $\begin{array}{l}\text { Goal setting, positive self-talk, self-motivation, self-efficacy, } \\
\text { optimism, self-confidence, stress, social support, athletic } \\
\text { identity }\end{array}$ \\
\hline Flanagan et al. (2015) [68] & Narrative & Not specified & Not assessed & N/A & $\begin{array}{l}\text { Self-efficacy, self-motivation, athletic identity, social } \\
\text { support, fear of reinjury, confidence, optimism/pessimism, } \\
\text { goal setting, positive self-talk }\end{array}$ \\
\hline Mendonza et al. (2007) [59] & Systematic & Until 2006 & Not assessed & 7 & $\begin{array}{l}\text { Self-motivation, social support, athletic identity, goal } \\
\text { setting, positive self-talk, situational stability, stability, } \\
\text { personal control }\end{array}$ \\
\hline $\begin{array}{l}\text { Sims and Mulcahey } \\
\text { (2018) [69] }\end{array}$ & Narrative & Not specified & Not assessed & N/A & $\begin{array}{l}\text { Self-confidence, optimism, self-motivation, locus of } \\
\text { control, athletic identity, sex difference in psychology }\end{array}$ \\
\hline $\begin{array}{l}\text { Spetch and Kolt } \\
\text { (2001) [21] }\end{array}$ & Narrative & Not specified & Not assessed & N/A & Stress, self-motivation \\
\hline $\begin{array}{l}\text { te Wierike et al. } \\
\text { (2013) [60] }\end{array}$ & Systematic & $2001-2011$ & Good & 2 & $\begin{array}{l}\text { Self-efficacy, age and sex effect on psychology, low } \\
\text { confidence/self-esteem, social support, goal setting, } \\
\text { positive self-talk, avoidance coping }\end{array}$ \\
\hline
\end{tabular}

Methodological quality refers to the outcome or presence of the quality appraisal undertaken by the review not the authors of this study. The key concepts list all of the psychological concepts addressed by each review in relation to psychological variables and adherence to rehabilitation

[70], counselling utility [71] and goal setting, imagery and positive self-talk [72]. Their correlation with rehabilitation adherence is detailed below and varies depending on the concept, age of participants or the setting of rehabilitation (clinic or home based).

Self-motivation was associated with home exercise completion [62, 71, 74]; this was true for older participants only in one study [73]. A high athletic identity in younger patients was associated with home exercise completion [73]. However, in two studies, athletic identity was not correlated with adherence to clinic or home-based exercise [62, 75]; except on days with high-stress, participants with high athletic identity completed more exercises [75].

Social support was not found to be significantly related to home exercise completion [62], except in older participants [73]. High stress and mood disturbance were negatively associated with home exercise completion. Neuroticism was not related to adherence, and participants with low pessimism were able to complete more prescribed exercises on days where they had more pain [75]. Goal setting and positive self-talk were significant positive correlates to home exercise adherence [72]. These were not related to clinic attendance or cryotherapy completion [72]. Autonomy had a positive relationship with rehabilitation adherence [74], and the Big 5 personality traits of agreeableness and conscientiousness were significantly correlated with adherence measures [74]. The theory of planned behaviour [70], imagery [72] and counselling sessions [71] did not correlate with rehabilitation adherence or participation.

\section{Summary}

There are a variety of psychological variables which may affect a person's adherence to rehabilitation; however, we did not investigate whether interventions to address these factors would lead to an increase in adherence. Further research aimed at addressing these factors and the effect that they have on rehabilitation adherence and subsequent patient outcomes is warranted.

\section{Patient Perceptions}

Table 9 details the thematic synthesis of patientperceived barriers to and facilitators of rehabilitation. Fifteen original studies were included in the analysis. Eight studies used a qualitative methodology $[15,20$, 80-85], four mixed methods [30, 77-79], one pilot RCT [61], one case series [71] and one prospective cohort study [86]. Fifty-five raw themes were categorised into three overall themes (environmental, personal and 


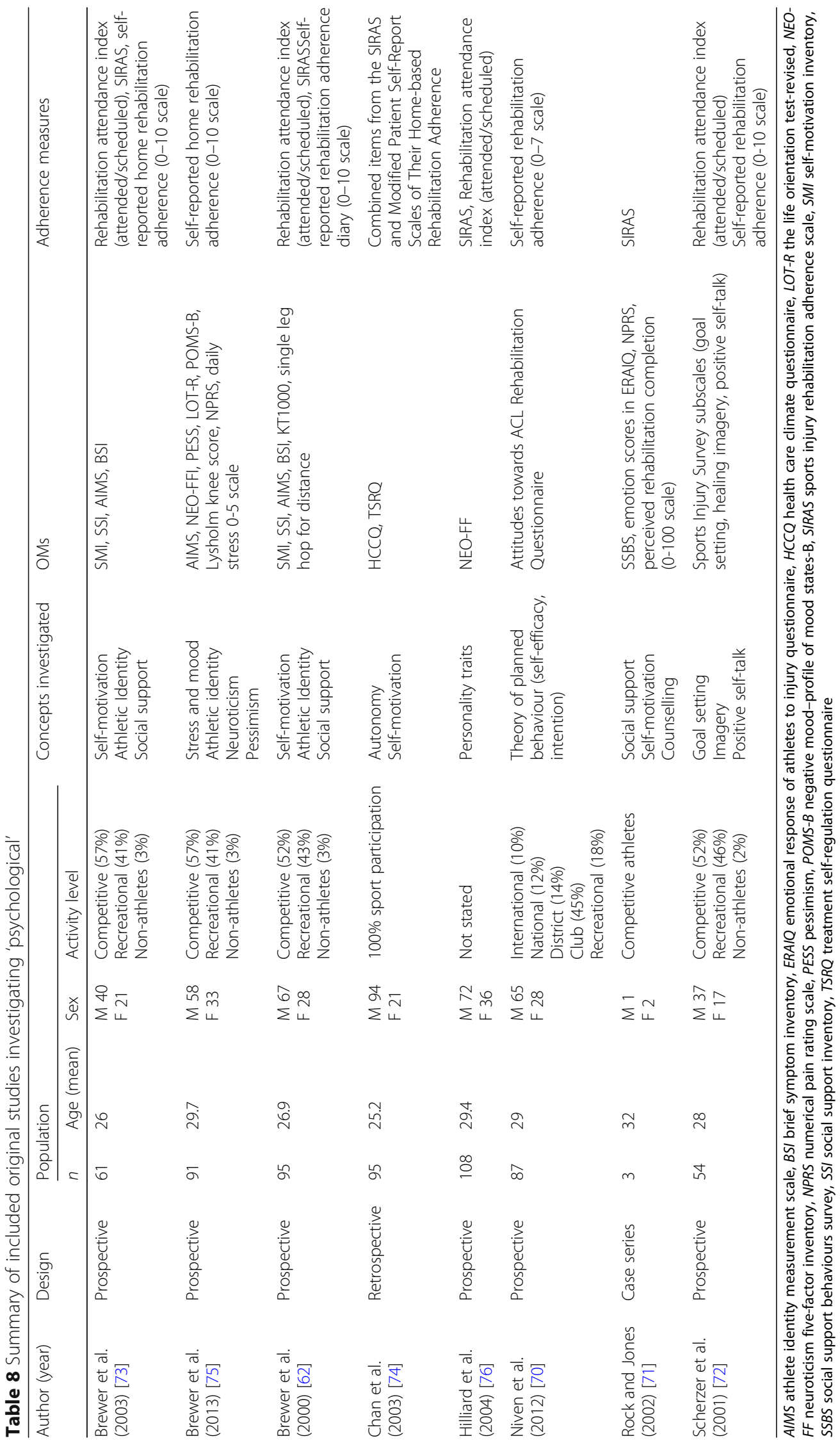


treatment-related) and nine sub-themes as detailed in Table 10.

Each theme was tallied on the number of times it was mentioned across the literature. A theme was only tallied once per article. The tally does not imply the weight of the barrier or facilitator on the subjects but only how often the factor has emerged in the research. Under the personal category, any theme relating to the mental and emotional state of a person, affecting, or arising in the mind was classified as psychological. However, any theme involving, or relating to, exhibiting a behaviour was categorised as behavioural. A factor could be both a facilitator and barrier. For example, interaction with family and friends may be a barrier if it involved sympathy, caution and worry from family and friends, but a facilitator if it involved support, motivation and encouragement.

Treatment-related factors were mentioned 82 times across three sub-themes (delivery of care, digital health and group rehabilitation) consisting of 32 raw themes; 36 mentions as a barrier to and 46 mentions as a facilitator of rehabilitation. Personal factors were mentioned 51 times across three sub-themes (psychological, physiological and behavioural), consisting of 19 raw themes; 28 mentions as a barrier and 23 mentions as a facilitator. Environmental factors were mentioned 19 times across two sub-themes (social and societal), consisting of four raw themes; 11 mentions as a barrier and eight mentions as a facilitator.

The most common raw themes arising in the literature as either a barrier or facilitator of rehabilitation were therapeutic relationship $(n=11)$, interaction with family and friends $(n=9)$, self-motivation $(n=9)$, fear of reinjury or return to sport $(n=7)$, organisation/lack of time $(n=6)$, interpersonal comparison $(n=6)$, interaction with team and coaches $(n=5)$, access to facilities and equipment $(n=4)$, expectations $(n=4)$, pain, weakness or illness $(n=4)$, length and commitment of rehabilitation $(n=4)$ and enjoyment $(n=4)$.

\section{Summary}

These results signify the key role the treating health practitioner plays in setting an appropriate rehabilitation environment to reduce treatment-related barriers to and enhance facilitators of rehabilitation but also support the athlete with a strong therapeutic relationship which fosters motivation and enjoyment. Specific personal factors related to the individual may be able to be addressed through therapeutic exercises (e.g. fear of reinjury) or may require tailored interventions or alternative professionals to facilitate rehabilitation. Social and societal factors also play a key role but are harder to influence by the practitioner.

\section{Other factors}

The three included original studies investigated associations between clinician experience and qualification [87], graft choice and meniscal injury [30] and participant sport [70] on rehabilitation adherence (Table 10).

To determine physiotherapist practice patterns, Greenberg et al. (2018) surveyed 1074 physiotherapists from the USA. They found clinicians with less clinical experience, higher volumes of patients post ACL reconstruction and an orthopaedic clinical specialist or sports clinical specialist certification deliver a longer overall duration of clinical care more in line with clinical recommendations [87].

In terms of graft choice and meniscus injury, Dempsey et al. (2019) found that competitive and recreational athletes who received a BPTB graft completed more days of rehabilitation per week and had more total visits compared with patients who received an HT graft; however, meniscal procedures did not correlate with rehabilitation quantity [30].

In a prospective study, Niven et al. (2012) found variation in the adherence levels across different sports, indicating that Gaelic football, hockey, rugby and soccer players consistently adhered well, whereas motocross participants were poor adherers [70]. The level of sport had a positive relationship, indicating that a lower level of participation was associated with higher adherence levels [70].

\section{Summary}

Newly graduated and specialty trained therapists may be more cognisant of current evidence and delivery care more in line with current recommendations. Although patients with BPTB graft attended more often, it is unclear what this may be due to and the implications for rehabilitation adherence. Finally, it is unclear as to the reasons why different sports have different levels of adherence.

\section{Discussion}

Participation in ACL rehabilitation is considered critical to facilitate return to sport $[14,51,88]$. In this scoping review, 71 articles relating to adherence and participation in ACL rehabilitation published between 1997 and 2019 were identified. A key finding of this review was that a longer duration of supervised evidence-based rehabilitation is correlated with more favourable outcomes post ACL reconstruction; however, the optimal frequency of rehabilitation supervision and the level of adherence required to a rehabilitation program is yet to be determined. It is reasonable to conclude that from current evidence, a minimally or moderately supervised rehabilitation program is at least as effective as a fully supervised high-frequency rehabilitation program. 
Table 9 Frequency of mention count for each theme identified in the synthesis of included original studies investigating 'patient perceptions'

\begin{tabular}{|c|c|c|c|}
\hline Factor & Barrier & Facilitator & Total \\
\hline Environment & 11 & 8 & 19 \\
\hline Social & 6 & 8 & 14 \\
\hline Interaction with family and friends & 3 & 6 & 9 \\
\hline Interaction with team and coaches & 3 & 2 & 5 \\
\hline Societal & 5 & 0 & 5 \\
\hline Access to facilities and equipment & 4 & & 4 \\
\hline Access to skilled providers & 1 & & 1 \\
\hline Personal & 28 & 23 & 51 \\
\hline Psychological & 16 & 15 & 31 \\
\hline Fear & 7 & & 7 \\
\hline Self-motivation (low/high) & 4 & 5 & 9 \\
\hline Met or unmet expectations & 2 & 2 & 4 \\
\hline Restlessness and impatience & 1 & & 1 \\
\hline Hopelessness/Belief & 1 & 1 & 2 \\
\hline Previous experience (bad/good) & 1 & 1 & 2 \\
\hline Progress changeability & & 1 & 1 \\
\hline Acceptance & & 1 & 1 \\
\hline Positive attitude & & 2 & 2 \\
\hline Feeling appreciated & & 1 & 1 \\
\hline Luck & & 1 & 1 \\
\hline Physiological & 6 & 2 & 8 \\
\hline Pain, weakness and illness & 4 & & 4 \\
\hline Significant injury & 1 & & 1 \\
\hline Second injury & 1 & & 1 \\
\hline Maintain health and fitness & & 2 & 2 \\
\hline Behavioural & 6 & 6 & 12 \\
\hline Organisation/lack of time (poor/good) & 5 & 1 & 6 \\
\hline Goal setting & 1 & 2 & 3 \\
\hline Persistence & & 2 & 2 \\
\hline Distraction (new activities) & & 1 & 1 \\
\hline Treatment-related & 36 & 46 & 82 \\
\hline Delivery of care & 18 & 13 & 31 \\
\hline Length and commitment of rehabilitation & 4 & & 4 \\
\hline Non-sport specific exercise & 2 & & 2 \\
\hline Restrictions in activities & 2 & & 2 \\
\hline Enjoyment & 2 & 2 & 4 \\
\hline Patient control (low/high) & 2 & 1 & 3 \\
\hline Insurance & 2 & 1 & 3 \\
\hline Assessment of progress & 1 & 3 & 4 \\
\hline Speed of progression of exercises (slow/fast) & 1 & 1 & 2 \\
\hline Early therapist discharge & 1 & & 1 \\
\hline Cost & 1 & & 1 \\
\hline Individualised program & & 3 & 3 \\
\hline
\end{tabular}


Table 9 Frequency of mention count for each theme identified in the synthesis of included original studies investigating 'patient perceptions' (Continued)

\begin{tabular}{|c|c|c|c|}
\hline Factor & Barrier & Facilitator & Total \\
\hline Comfort and convenience & & 1 & 1 \\
\hline Cryotherapy & & 1 & 1 \\
\hline Provider factors & 12 & 13 & 25 \\
\hline Therapeutic relationship & 4 & 7 & 11 \\
\hline Physiotherapist as a guide and coordinator & 2 & 2 & 4 \\
\hline Coordination between providers & 3 & 2 & 5 \\
\hline Information availability & 3 & 2 & 5 \\
\hline Digital health & 3 & 8 & 11 \\
\hline Poor accessibility & 1 & & 1 \\
\hline Uncertainty of technique and safety & 1 & & 1 \\
\hline Familiarity with digital devices & 1 & 1 & 2 \\
\hline Blended care model & & 2 & 2 \\
\hline Informational and instructive & & 2 & 2 \\
\hline Reminder for exercise completion & & 2 & 2 \\
\hline Viewed as the future & & 1 & 1 \\
\hline Group rehabilitation & 3 & 12 & 15 \\
\hline Interpersonal comparison & 2 & 4 & 6 \\
\hline Social interaction & 1 & 1 & 2 \\
\hline Informational support & & 2 & 2 \\
\hline Fun and enjoyable & & 1 & 1 \\
\hline Motivation and support & & 1 & 1 \\
\hline Innovative & & 1 & 1 \\
\hline Obligation & & 1 & 1 \\
\hline Adequate monitoring and adaptability & & 1 & 1 \\
\hline
\end{tabular}

Bold text highlights each key theme and sub-theme

Furthermore, many factors were associated with a patient's ability to adhere to and participate in rehabilitation. Psychological factors of self-motivation, athletic identity, stress and mood disturbance, goal setting, positive self-talk and the personality traits of optimism, agreeableness and conscientiousness were associated with rehabilitation adherence. Numerous patientperceived barriers to and facilitators of rehabilitation were identified. The most common were the therapeutic relationship, interaction with family and friends, selfmotivation, fear of reinjury and organisation/lack of time.

Table 10 Summary of included original studies investigating 'other factors'

\begin{tabular}{|c|c|c|c|c|c|c|c|c|}
\hline \multirow[t]{2}{*}{ Author (year) } & \multirow[t]{2}{*}{ Design } & \multicolumn{4}{|c|}{ Population } & \multirow{2}{*}{$\begin{array}{l}\text { Concepts } \\
\text { investigated }\end{array}$} & \multirow[t]{2}{*}{ OMs } & \multirow[t]{2}{*}{ Comparators } \\
\hline & & $n$ & $\begin{array}{l}\text { Age } \\
\text { (mean) }\end{array}$ & Sex & Activity level & & & \\
\hline $\begin{array}{l}\text { Dempsey } \\
\text { et al. (2019) [30] }\end{array}$ & $\begin{array}{l}\text { Mixed } \\
\text { methods }\end{array}$ & 60 & 29.7 & $\begin{array}{l}\text { M } \\
31 \\
\text { F } 29\end{array}$ & $\begin{array}{l}\text { Competitive } \\
(57 \%) \\
\text { Recreational } \\
(41 \%) \\
\text { Non-athletes } \\
(3 \%)\end{array}$ & $\begin{array}{l}\text { Graft type } \\
\text { Meniscus injury }\end{array}$ & Sessions attended & $\begin{array}{l}\text { BPTB or HS graft } \\
\text { Meniscus injury }\end{array}$ \\
\hline $\begin{array}{l}\text { Greenberg } \\
\text { et al. (2018) [87] }\end{array}$ & Cross-sectional & 1074 & N/A & N/A & N/A & $\begin{array}{l}\text { Physiotherapist } \\
\text { practice patterns }\end{array}$ & N/A & N/A \\
\hline $\begin{array}{l}\text { Niven } \\
\text { et al. (2012) [70] }\end{array}$ & Prospective & 87 & 29 & $\begin{array}{l}M \\
65 \\
F 28\end{array}$ & Not stated & $\begin{array}{l}\text { Level and } \\
\text { type of sport }\end{array}$ & $\begin{array}{l}\text { Attitudes towards } \mathrm{ACL} \\
\text { Rehabilitation Questionnaire }\end{array}$ & $\begin{array}{l}\text { Self-reported } \\
\text { rehabilitation } \\
\text { adherence (0-7 scale) }\end{array}$ \\
\hline
\end{tabular}

$M$ male, BPTB bone patella tendon bone, $F$ female, $H S$ hamstring, OCS orthopaedic certified specialist, SCS sport certified specialist 
For the researcher and clinician, the results of our scoping review highlight the need to develop appropriate rehabilitation protocols that not only develop the physical capabilities of patients but also take into account patients' circumstances and psychology, which may pose barriers to achieving a successful outcome. Aspects of rehabilitation may need to be varied depending on the individual presenting.

\section{How Much Supervision Is Required, and For How Long?}

It would be premature to conclude that reducing rehabilitation supervision during ACL reconstruction is required. Current practice patterns in Australia reflect a decreasing frequency of supervised rehabilitation from once or twice per week in the early phases, to less frequent visitation with a focus on independent exercise with periodic review as rehabilitation progresses [89]. The evidence in this review is inconclusive as to whether this is the most appropriate way to manage patients.

Based on our results, the duration of supervised rehabilitation may be more important than frequency. Supervised rehabilitation should begin shortly after surgery [57], continue for greater than 6 months (ideally 9-12 months) and include a tailored gym program, landing, agility, on-field rehabilitation and a structured return to sport. It appears that two patients performing the same rehabilitation program can achieve the same outcome regardless of supervision or adherence level; however, it remains to be seen whether patients have the knowledge and skills to complete rehabilitation at the appropriate intensity to achieve return to sport criteria without appropriate supervision [55].

Recent original studies have demonstrated that even with well-controlled and implemented rehabilitation, most athletes fail to meet discharge criteria [90]. Furthermore, in the community, only $30 \%$ of patients complete any form of rehabilitation beyond 6 months [91] and only $5 \%$ of people complete evidence-based rehabilitation. Edwards et al. (2017) demonstrated only $21 \%$ of patients who had completed rehabilitation and $5 \%$ of patients who had not completed rehabilitation passed a RTS test battery before RTS [46]. Therefore, even if patients do complete rehabilitation, the end phase of rehabilitation is typically not extensive or specific enough, failing to expose patients to specific training loads and training characteristics necessary before they return to unrestricted sport [90]. Due to the knowledge and skills required to execute latestage rehabilitation to a sufficient standard and intensity, a higher level of supervision may be needed in the later phases to meet return to sport criteria and reduce the risk of reinjury $[50,51,55]$.

All original studies which showed a positive relationship between supervised rehabilitation frequency and outcomes were published in the last 4 years. This fact may suggest that modern rehabilitation programs may require more guidance from a clinician. Age may also play a role in the frequency of supervision required. Younger patients, particularly under 18 , may require a higher frequency to achieve successful outcomes by providing extra guidance on exercises, goals and motivation to adhere to post-operative rehabilitation [43, 46, 64].

Clinician knowledge may also play a role in achieving a successful outcome. Clinicians familiar with current best practice who service a higher volume of patients who have undergone ACL reconstruction are more likely to provide evidence-based care, while less familiar clinicians may be at risk of prematurely discharging patients before meeting established RTS criteria [87]. This may be due to a lack of confidence, skills or resources in the performance of late stage rehabilitation and return to sport criteria. Clinicians, therefore, need to be aware of their own limitations and potentially refer to other health professionals.

A final point to consider is that the increasing demand for cost-effective health care interventions is leading to the development of more unsupervised rehabilitation protocols [25]. Rehabilitation needs to be both effective and economical. There are substantial financial advantages of more patient-directed rehabilitation in reducing costs for the appointment, travel time, inconvenience, time off work and comfort [25, 34, 35]. This presents a tough challenge for clinicians to ensure that patients have access to appropriate rehabilitation to achieve functional and sporting goals, but not increase the undue financial burden upon the patient, health care system and industry [37]. No articles in this review included a costbenefit analysis, which would aid in the development of a more robust research base and allow us to gain further insight into how to minimise costs and maximise outcome.

When designing future research to examine the adherence and outcome relationship, it is critical that researchers consider the definition of adherence, parameter, adherence measure and the value for acceptable adherence [91]. The studies detailed in this review [61-64] used a variety of measures including self-report diary, sessions attended, adherence within session (SIRAS) and hidden tape player counters. Multiple systematic reviews have highlighted a lack of a single valid and reliable measurement tool of adherence means that the relative effectiveness of interventions is difficult to compare across studies [92-94]. In a recent systematic review by Bailey et al. (2018) [91], the authors concluded there is a lack of sufficient consistency in adherence parameters, measures and values to inform a definition of adherence to therapeutic exercise or the required content of a suitable measure. The definition by Frost et al. (2017) 
('the extent to which individuals undertake prescribed behaviour accurately and at the agreed frequency, intensity and duration' [95]) is provided as a starting point to develop an appropriate adherence measure as it includes the measures of frequency, duration, intensity and accuracy [91].

\section{Can We Improve Rehabilitation Adherence and Participation?}

Despite our improved understanding of what components need to be included within an evidence-based ACL rehabilitation [14], little consideration is given to why patients cease rehabilitation and the barriers which patients face in their rehabilitation journey [30].

Psychological factors, particularly fear of reinjury, are the most significant contributor to not returning to sport [96]. The results of this review support the notion that psychological variables contribute to patients ceasing or failing to adhere to rehabilitation. Self-efficacy was consistently reported as a significant mediator of successful surgery and rehabilitation [61]. Strategies to enhance patients' self-efficacy have the potential to improve related barriers to participation, such as selfconfidence, locus of control, autonomy support and stress and mood disturbance [97]. Likewise, the enhancement of patient self-motivation improves the chance they will persist with rehabilitation [98]. Patients can draw extrinsic motivation from the physiotherapist and rehabilitation program (e.g. progressing exercises, reassessing progress, goal setting, social and informational support) and therefore, increase their likelihood to participate in and progress through an appropriate duration of rehabilitation $[58,59]$. Put together with the appropriate progression of exercises to expose patients to psychologically challenging but safe situations, fear of reinjury could also be reduced, increasing the likelihood of a return to sport and reducing reinjury [60]. Clinicians also need to be aware that some patients may require referral to an appropriate health care professional to receive specialised psychological care.

Especially due to the long rehabilitation process, by structuring or delivering rehabilitation in a manner that supports a positive psychological state (managing mood disturbance, enhancing and maintaining athletic identity and utilisation of goal setting and self-talk), many barriers to rehabilitation and return to sport can be overcome $[60,81,85]$. Further research into the utility of psychological intervention in ACL rehabilitation is needed [99].

\section{How Can the Clinician Help the Patient?}

Our results show a large number of patient-perceived barriers to and facilitators of rehabilitation. Many of the factors likely interact with each other, and by putting in place practices that either enhance facilitators or remove barriers, outcomes could be improved (Fig. 3).

As exemplified in our results, the physiotherapist plays a significant role in driving recovery by offering motivation, support, guidance, and encouragement while also providing informational support. It is also the physiotherapist's responsibility to set realistic expectations and deliver a fun, progressive, sport-specific program for the individual with regular goal setting and reassessment. The physiotherapist can also assist in overcoming the physiological barriers to rehabilitation, such as pain and reduced health and fitness due to injury.

Group-based rehabilitation has the potential to overcome many of the barriers to and enhance facilitators of rehabilitation. Studies investigating group-based therapy demonstrated positive characteristics, including an enjoyable, cost-effective, social, supportive and motivating environment $[80,85]$. Particularly with advancements in technology, the support of digital health technology is becoming increasingly valuable. By supporting face to face interactions, it provides a useful adjunct to improve exercise adherence, increase engagement, enhance the therapeutic relationship and provide informational support to

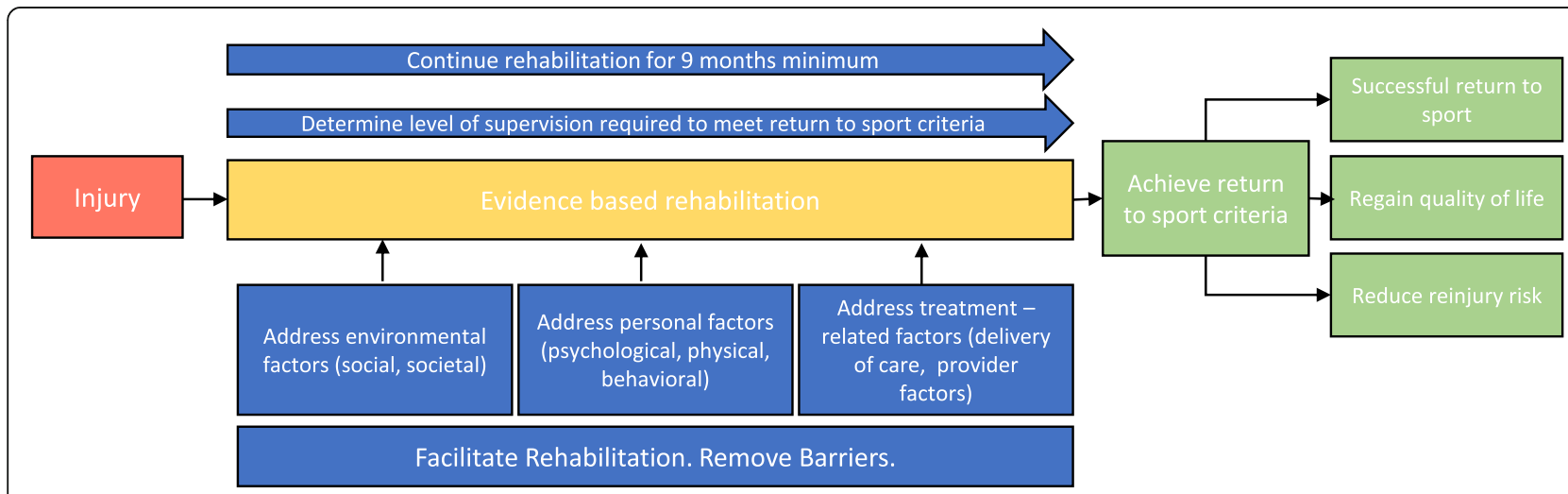

Fig. 3 Thematic model depicting individual considerations required when planning ACL rehabilitation 
what is required at each stage, assisting in setting realistic expectations [81].

Environmental factors are harder to control as they are often out of the control of the treating physiotherapist. Physiotherapists working within team environments can assist by providing coaches and teammates with the appropriate information to facilitate inclusion and interaction with the main training group. If the physiotherapist has interaction with family members and friends, positive supportive behaviours can also be reinforced. Geographic constraints that prevent access to appropriate facilities and providers pose a particular challenge. Digital health may be an area of future research to address this domain.

\section{Strengths and Limitations}

This review is the first to address the effects of rehabilitation adherence and participation on ACL rehabilitation outcome. We were then able to provide the reader with potential influencing factors which create barriers to or facilitate rehabilitation. The review was also conducted according to recognised standards for scoping review following the development and publication of an a priori protocol.

The methodological quality of the articles was not assessed as per guidelines for conducting scoping reviews $[16,17]$. Many studies were deemed as methodologically poor in quality, suggesting that more work is needed in developing good quality research in this area. There was no date limit on the search or inclusion. Included articles may not reflect contemporary practice due to changes in practice patterns through time.

When assessing the evidence for the frequency of supervised rehabilitation, it was not determined whether any cohort of patients achieved a successful outcome from their rehabilitation. Lynch et al. (2013) detailed the criteria for defining a successful outcome after ACL reconstruction. These are the absence of giving way, patient return to sport status, the absence of knee joint effusion, quadriceps muscle strength symmetry and meeting patient-reported outcome benchmarks [100]. Due to the outcome measure heterogeneity, it was not possible to evaluate whether a successful rehabilitation outcome was achieved. The level of compliance of patients in the included original studies within the frequency analysis to the home-based rehabilitation prescribed was also unknown [23].

Only articles published in English were available for inclusion, introducing a publication bias. Only one author screened, selected and extracted the data from the studies, potentially missing articles or introducing bias to data presented. The articles were categorised and analysed based on the author determined constructs. The categorisation may have been different for different authors.
Considerable heterogeneity between studies in outcome measures used, rehabilitation timeframes and programs reduced the ability to compare results directly. Most studies reported on participants over the age of 25 , reducing the ability to draw conclusions for patients in a younger age group who typically have higher return to sport goals. Poor reporting of activity level and sport of the included participants leads to uncertainty in identifying factors relevant to specific athletes, sports or activity levels. Studies were from a variety of countries, introducing biases into the results due to different standards of care and access to health services. However, the review provides a comprehensive analysis of the current state of knowledge and areas where further work is needed to facilitate better rehabilitation practices.

\section{Conclusion}

This scoping review highlighted a broad spectrum of factors the clinician should consider when facilitating a patient's rehabilitation after ACL reconstruction. Growing evidence suggests a longer duration of supervised rehabilitation involving agility, landing and gym exercises, and a supervised return to activity or sport is required to achieve functional and return to sport goals. The lack of conclusive evidence to support a specific supervised rehabilitation frequency fails to provide appropriate guidance to treating physiotherapists to deliver more optimal care.

Identification of the barriers to and facilitators of adherence and participation in ACL rehabilitation provides an opportunity for further research to be conducted to address personal, environmental, and treatment-related factors. Taking these factors into account increases the likelihood of patients complying with current best evidence rehabilitation to improve outcomes such as return to sport rates and reinjury.

\section{Supplementary information}

Supplementary information accompanies this paper at https://doi.org/10. 1186/s40798-020-00258-7.

\section{Additional file 1. Search}

\section{Abbreviations}

ACL: Anterior cruciate ligament; RTS: Return to sport; PRISMA-SCR: Preferred Reporting Items for Systematic Reviews and Meta-Analysis Extension for Scoping Reviews; RCT: Randomised controlled trial; BPTB: Bone patella tendon bone; OM: Outcome measure; KOS-ADL: Knee Outcome ScoreActivities of Daily Living; SIRAS: Sport Injury Rehabilitation Adherence Scale

\section{Acknowledgements}

Not applicable.

\section{Authors' Contributions}

AW made contributions to the design of the work, interpretation of data, drafting, writing for critical revision for intellectual content. WH and AL made contributions to the design of the study, interpretation of data and revision of the work. All authors gave final approval for the final version and agreed to be accountable for all aspects of the work. 


\section{Funding}

Adam Walker is supported by an Australian Government Research Training Program Scholarship with the review to contribute towards a Higher Degree by Research Degree (Doctor of Philosophy). No other specific sources of funding were used to assist in the preparation of this article.

\section{Availability of Data and Materials}

The datasets used and/or analysed during the current study are available from the corresponding author on reasonable request.

\section{Ethics Approval and Consent to Participate}

\section{Not applicable.}

\section{Consent for Publication}

Not applicable.

\section{Competing Interests}

Adam Walker is a practicing physiotherapist associated with a commercial entity which provides rehabilitation services to patients who have had an $\mathrm{ACL}$ reconstruction. Wayne Hing and Anna Lorimer declare that they have no conflicts of interest relevant to the content of this review.

Received: 9 February 2020 Accepted: 30 June 2020

Published online: 17 July 2020

\section{References}

1. Koga H, Nakamae A, Shima Y, Iwasa J, Myklebust G, Engebretsen L, et al. Mechanisms for noncontact anterior cruciate ligament injuries: knee joint kinematics in 10 injury situations from female team handball and basketball. The American journal of sports medicine. 2010;38(11):2218-25.

2. van Melick N, van Cingel RE, Brooijmans F, Neeter C, van Tienen T, Hullegie $W$, et al. Evidence-based clinical practice update: practice guidelines for anterior cruciate ligament rehabilitation based on a systematic review and multidisciplinary consensus. British Journal of Sports Medicine 2016:bjsports2015-095898.

3. Welling W, Benjaminse A, Seil R, Lemmink K, Zaffagnini S, Gokeler A. Low rates of patients meeting return to sport criteria 9 months after anterior cruciate ligament reconstruction: a prospective longitudinal study. Knee Surgery, Sports Traumatology, Arthroscopy. 2018:1-9.

4. Filbay S, Ackerman I, Russell T, Crossley K. Return to sport matters-longerterm quality of life after $\mathrm{ACL}$ reconstruction in $\mathrm{p}$ eople with knee difficulties. Scandinavian Journal of Medicine and Science in Sports. 2017;27(5):514-24.

5. Janssen KW, Orchard JW, Driscoll TR, van Mechelen W. High incidence and costs for anterior cruciate ligament reconstructions performed in Australia from 2003-2004 to 2007-2008: time for an anterior cruciate ligament register by Scandinavian model? Scandinavian journal of medicine \& science in sports. 2012;22(4):495-501.

6. Culvenor AG, Collins NJ, Guermazi A, Cook JL, Vicenzino B, Khan KM, et al. Early knee osteoarthritis is evident one year following anterior cruciate ligament reconstruction: a magnetic resonance imaging evaluation. Arthritis Rheumatol. 2015;67(4):946-55.

7. Culvenor AG, Barton CJ. ACL injuries: the secret probably lies in optimising rehabilitation. British Journal of Sports Medicine. 2018: bjsports-2017-098872.

8. Ardern CL, Taylor NF, Feller JA, Webster KE. Fifty-five per cent return to competitive sport following anterior cruciate ligament reconstruction surgery: an updated systematic review and meta-analysis including aspects of physical functioning and contextual factors. British Journal of Sports Medicine. 2014;48(21):1543-52.

9. Wiggins AJ, Grandhi RK, Schneider DK, Stanfield D, Webster KE, Myer GD Risk of secondary injury in younger athletes after anterior cruciate ligament reconstruction: a systematic review and meta-analysis. The American Journal of Sports Medicine. 2016;44(7):1861-76.

10. Morgan MD, Salmon LJ, Waller A, Roe JP, Pinczewski LA. Fifteen-year survival of endoscopic anterior cruciate ligament reconstruction in patients aged 18 years and younger. The American Journal of Sports Medicine. 2016;44(2): 384-92.

11. Grindem H, Arundale AJ, Ardern CL. Alarming underutilisation of rehabilitation in athletes with anterior cruciate ligament reconstruction: four ways to change the game. British journal of sports medicine. 2018;52(18):1162-3.
12. Beischer S, Hamrin Senorski E, Thomee C, Samuelsson K, Thomee R. Young athletes return too early to knee-strenuous sport, without acceptable knee function after anterior cruciate ligament reconstruction. Knee Surg Sports Traumatol Arthrosc. 2018;26(7):1966-74.

13. Anderson MJ, Browning WM, Urband CE, Kluczynski MA, Bisson LJ. A Systematic Summary of Systematic Reviews on the Topic of the Anterior Cruciate Ligament. Orthopaedic journal of sports medicine. 2016;4(3):23.

14. van Melick N, van Cingel RE, Brooijmans F, Neeter C, van Tienen T, Hullegie W, et al. Evidence-based clinical practice update: practice guidelines for anterior cruciate ligament rehabilitation based on a systematic review and multidisciplinary consensus. British journal of sports medicine. 2016;50(24): 1506-15.

15. Paterno MV, Schmitt LC, Thomas S, Duke N, Russo R, Quatman-Yates CC Patient and parent perceptions of rehabilitation factors that influence outcomes after anterior cruciate ligament reconstruction and clearance to return to sport in adolescents and young adults: a qualitative investigation. J Orthop Sports Phys Ther. 2019:1-35

16. Arksey H, O'Malley L. Scoping studies: towards a methodological framework. International journal of social research methodology. 2005;8(1):19-32.

17. Tricco AC, Lillie E, Zarin W, O'Brien KK, Colquhoun H, Levac D, et al. PRISMA extension for scoping reviews (PRISMA-SCR): checklist and explanation. Annals of internal medicine. 2018;169(7):467-73.

18. Peters M, Godfrey C, Mclnerney P, Soares CB, Khalil H, Parker D. Methodology for JBI scoping reviews. The Joanna Briggs Institute Reviewers manual 2015: The Joanna Briggs Institute; 2015. p. 3-24

19. Thomas J, Harden A. Methods for the thematic synthesis of qualitative research in systematic reviews. BMC Med Res Methodol. 2008;8:45.

20. Scott SM, Perry MA, Sole G. "Not always a straight path": patients' perspectives following anterior cruciate ligament rupture and reconstruction. Disabil Rehabil. 2018;40(19):2311-7.

21. Spetch LA, Kolt GS. Adherence to sport injury rehabilitation: implications for sports medicine providers and researchers. Physical Therapy in Sport. 2001; 2(2):80-90.

22. Andersson D, Samuelsson K, Karlsson J. Treatment of anterior cruciate ligament injuries with special reference to surgical technique and rehabilitation: an assessment of randomized controlled trials. arthroscopythe Journal of Arthroscopic and Related Surgery. 2009;25(6):653-685.

23. Coppola SM, Collins SM. Is physical therapy more beneficial than unsupervised home exercise in treatment of post surgical knee disorders? A systematic review. Knee. 2009;16(3):171-5.

24. Kruse LM, Gray B, Wright RW. Rehabilitation after anterior cruciate ligament reconstruction: a systematic review. The Journal of bone and joint surgery American volume. 2012;94(19):1737-48.

25. Papalia R, Vasta S, Tecame A, D'Adamio S, Maffulli N, Denaro V. Home-based vs supervised rehabilitation programs following knee surgery: a systematic review. British Medical Bulletin. 2013;108(1):55-72.

26. Risberg MA, Lewek M, Snyder-Mackler L. A systematic review of evidence for anterior cruciate ligament rehabilitation: How much and what type? Physical Therapy in Sport. 2004;5(3):125-45.

27. Trees $A H$, Howe TE, Dixon J, White L. Exercise for treating isolated anterior cruciate ligament injuries in adults. Cochrane Database Syst Rev. 2005;4:41

28. Wright RW, Preston E, Fleming BC, Amendola A, Andrish JT, Bergfeld JA, et al. A systematic review of anterior cruciate ligament reconstruction rehabilitation: part I: continuous passive motion, early weight bearing, postoperative bracing, and home-based rehabilitation. J Knee Surg. 2008; 21(3):217-24.

29. Lobb R, Tumilty S, Claydon LS. A review of systematic reviews on anterior cruciate ligament reconstruction rehabilitation. Physical therapy in sport : official journal of the Association of Chartered Physiotherapists in Sports Medicine. 2012;13(4):270-8.

30. Dempsey IJ, Norte GE, Hall M, Goetschius J, Slater LV, Cancienne JM, et al. Relationship Between Physical Therapy Characteristics, Surgical Procedure, and Clinical Outcomes in Patients After ACL Reconstruction. J Sport Rehabil. 2019;28(2):171-9.

31. Beard DJ, Dodd CA. Home or supervised rehabilitation following anterior cruciate ligament reconstruction: a randomized controlled trial. J Orthop Sports Phys Ther. 1998:27(2):134-43.

32. Christensen JC, Miller CJ, Burns RD, West HS. Effect of physical therapy visits on clinical outcomes following anterior cruciate ligament reconstruction with and without concurrent meniscal repair. J Sport Rehabil. 2018:1-9. 
33. Darain H, Alkitani A, Yates C, Bailey A, Roberts S, Coutts F, et al. Antecedent anterior cruciate ligament reconstruction surgery and optimal duration of supervised physiotherapy. J Back Musculoskelet Rehabil. 2015;28(4):877-82.

34. De Carlo MS, Sell KE. The effects of the number and frequency of physical therapy treatments on selected outcomes of treatment in patients with anterior cruciate ligament reconstruction. J Orthop Sports Phys Ther. 1997; 26(6):332-9.

35. Feller JA, Webster KE, Taylor NF, Payne R, Pizzari T. Effect of physiotherapy attendance on outcome after anterior cruciate ligament reconstruction: a pilot study. British journal of sports medicine. 2004;38(1):74-7.

36. Fischer DA, Tewes DP, Boyd JL, Smith JP, Quick DC. Home based rehabilitation for anterior cruciate ligament reconstruction. Clinical orthopaedics and related research. 1998;347:194-9.

37. Grant JA, Mohtadi NG. Two- to 4-year follow-up to a comparison of home versus physical therapy-supervised rehabilitation programs after anterior cruciate ligament reconstruction. The American journal of sports medicine 2010;38(7):1389-94.

38. Grant JA, Mohtadi NG, Maitland ME, Zernicke RF. Comparison of home versus physical therapy-supervised rehabilitation programs after anterior cruciate ligament reconstruction: a randomized clinical trial. The American journal of sports medicine. 2005;33(9):1288-97.

39. Han F, Banerjee A, Shen L, Krishna L. Increased compliance with supervised rehabilitation improves functional outcome and return to sport after anterior cruciate ligament reconstruction in recreational athletes. Orthopaedic journal of sports medicine. 2015;3(12):2325967115620770.

40. Hohmann E, Tetsworth K, Bryant A. Physiotherapy-guided versus homebased, unsupervised rehabilitation in isolated anterior cruciate injuries following surgical reconstruction. Knee Surg Sports Traumatol Arthrosc. 2011;19(7):1158-67.

41. Inacio MC, Cafri G, Funahashi TT, Maletis GB, Paxton EW. Type and frequency of healthcare encounters can predict poor surgical outcomes in anterior cruciate ligament reconstruction patients. International journal of medical informatics. 2016;90:32-9.

42. Lim JM, Cho JJ, Kim TY, Yoon BC. Isokinetic knee strength and proprioception before and after anterior cruciate ligament reconstruction: a comparison between home-based and supervised rehabilitation. J Back Musculoskelet Rehabil. 2019;32(3):421-9.

43. Miller CJ, Christensen JC, Burns RD. Influence of demographics and utilization of physical therapy interventions on clinical outcomes and revision rates following anterior cruciate ligament reconstruction. J Orthop Sports Phys Ther. 2017;47(11):834-44.

44. Przybylak K, Sibinski M, Domzalski M, Kwapisz A, Momaya AM, Zielinska M. Supervised physiotherapy leads to a better return to physical activity after anterior cruciate ligament reconstruction. J Sports Med Phys Fitness. 2018.

45. Revenas $\AA$, Johansson A, Leppert J. A randomized study of two physiotherapeutic approaches after knee ligament reconstruction. Advances in Physiotherapy. 2009:11(1):30-41.

46. Schenck RC Jr, Blaschak MJ, Lance ED, Turturro TC, Holmes CF. A prospective outcome study of rehabilitation programs and anterior cruciate ligament reconstruction. Arthroscopy : the journal of arthroscopic \& related surgery : official publication of the Arthroscopy Association of North America and the International Arthroscopy Association. 1997;13(3):285-90.

47. Treacy SH, Barron OA, Brunet ME, Barrack RL. Assessing the need for extensive supervised rehabilitation following arthroscopic $A C L$ reconstruction. American journal of orthopedics (Belle Mead, NJ). 1997;26(1):25-9.

48. Ugutmen E, Ozkan K, Kilincoglu V, Ozkan FU, Toker S, Eceviz E, et al. Anterior cruciate ligament reconstruction by using otogenous [correction of otogeneous] hamstring tendons with home-based rehabilitation. J Int Med Res. 2008:36(2):253-9.

49. Yu PHV, Wun YC, Yung SHP. Role of physiotherapy in preventing failure of primary anterior cruciate ligament reconstruction. Journal of Orthopaedics, Trauma and Rehabilitation. 2017;22:6-12.

50. Ebert JR, Edwards P, Yi L, Joss B, Ackland T, Carey-Smith R, et al. Strength and functional symmetry is associated with post-operative rehabilitation in patients following anterior cruciate ligament reconstruction. Knee Surg Sports Traumatol Arthrosc. 2018;26(8):2353-61.

51. Edwards P, Ebert J, Joss B, Annear P, Buelow J, Hewitt B. Patient characteristics and predictors of return to sport at 12 months after anterior cruciate ligament reconstruction: the importance of patient age and post-operative rehabilitation. Journal of Science and Medicine in Sport. 2017;20:78.
52. Krolikowska A, Czamara A, Reichert P. Between-limb symmetry during double-leg vertical hop landing in males an average of two years after $\mathrm{ACL}$ reconstruction is highly correlated with postoperative physiotherapy supervision duration. Appl Sci-Basel. 2018;8(12):19.

53. Krolikowska A, Czamara A, Szuba L, Reichert P. The effect of longer versus shorter duration of supervised physiotherapy after $A C L$ reconstruction on the vertical jump landing limb symmetry. Biomed Res Int. 2018;2018:7519467.

54. Krolikowska A, Reichert P, Czamara A, Krzeminska K. Peak torque angle of anterior cruciate ligament-reconstructed knee flexor muscles in patients with semitendinosus and gracilis autograft is shifted towards extension regardless of the postoperative duration of supervised physiotherapy. PLoS One. 2019;14(2):e0211825.

55. Krolikowska A, Sikorski L, Czamara A, Reichert P. Effects of postoperative physiotherapy supervision duration on clinical outcome, speed, and agility in males 8 months after anterior cruciate ligament reconstruction. Medical science monitor : international medical journal of experimental and clinical research. 2018;24:6823-31.

56. Krolikowska A, Sikorski L, Czamara A, Reichert P. Are the knee extensor and flexor muscles isokinetic parameters affected by the duration of postoperative physiotherapy supervision in patients eight months after $\mathrm{ACL}$ reconstruction with the use of semitendinosus and gracilis tendons autograft? Acta Bioeng Biomech. 2018;20(4):89-100.

57. Rosso F, Bonasia DE, Cottino U, Cambursano S, Dettoni F, Rossi R. Factors Affecting Subjective and Objective Outcomes and Return to Play in Anterior Cruciate Ligament Reconstruction: A Retrospective Cohort Study. Joints. 2018;6(1):23-32

58. Christino MA, Fantry AJ, Vopat BG. Psychological aspects of recovery following anterior cruciate ligament reconstruction. The Journal of the American Academy of Orthopaedic Surgeons. 2015;23(8):501-9.

59. Mendonza M, Patel H, Bassett S. Influences of psychological factors and rehabilitation adherence on the outcome post anterior cruciate ligament injury/surgical reconstruction. New Zealand Journal of Physiotherapy. 2007; 35(2):62-71

60. te Wierike SC, van der Sluis A, van den Akker-Scheek I, Elferink-Gemser MT, Visscher C. Psychosocial factors influencing the recovery of athletes with anterior cruciate ligament injury: a systematic review. Scandinavian journal of medicine \& science in sports. 2013;23(5):527-40.

61. Levinger $P$, Hallam K, Fraser D, Pile R, Ardern C, Moreira B, et al. A novel web-support intervention to promote recovery following Anterior Cruciate Ligament reconstruction: A pilot randomised controlled trial. Physical therapy in sport : official journal of the Association of Chartered Physiotherapists in Sports Medicine. 2017;27:29-37.

62. Brewer BW, Van Raalte JL, Cornelius AE, Petitpas AJ, Sklar JH, Pohlman MH, et al. Psychological factors, rehabilitation adherence, and rehabilitation outcome after anterior cruciate ligament reconstruction. Rehabilitation Psychology. 2000;45(1):20-37

63. Brewer BW, Cornelius AE, Van Raalte JL, Brickner JC, Sklar JH, Corsetti JR, et al. Rehabilitation adherence and anterior cruciate ligament reconstruction outcome. Psychology, Health and Medicine. 2004:9(2):163-75.

64. Pizzari T, Taylor NF, McBurney H, Feller JA. Adherence to rehabilitation after anterior cruciate ligament reconstructive surgery: Implications for outcome. Journal of Sport Rehabilitation. 2005;14(3):201-14.

65. Everhart JS, Best TM, Flanigan DC. Psychological predictors of anterior cruciate ligament reconstruction outcomes: a systematic review. Knee Surg Sports Traumatol Arthrosc. 2015;23(3):752-62.

66. Ardern CL, Kvist J, Webster KE. Psychological aspects of anterior cruciate ligament injuries. Operative Techniques in Sports Medicine. 2016;24(1):77-83.

67. Burland JP, Lepley AS, Cormier M, DiStefano LJ, Arciero R, Lepley LK. Learned helplessness after anterior cruciate ligament reconstruction: an altered neurocognitive state? Sports medicine (Auckland, NZ). 2019;49(5): 647-57.

68. Flanigan DC, Everhart JS, Glassman AH. Psychological factors affecting rehabilitation and outcomes following elective orthopaedic surgery. The Journal of the American Academy of Orthopaedic Surgeons. 2015;23(9):563-70.

69. Sims M, Mulcahey MK. Sex-specific differences in psychological response to injury and return to sport following $A C L$ reconstruction. JBJS Rev. 2018;6(7):7.

70. Niven A, Nevill A, Sayers F, Cullen M. Predictors of rehabilitation intention and behavior following anterior cruciate ligament surgery: an application of the Theory of Planned Behavior. Scandinavian journal of medicine \& science in sports. 2012;22(3):316-22. 
71. Rock JA, Jones MV. A preliminary investigation into the use of counseling skills in support of rehabilitation from sport injury. Journal of Sport Rehabilitation. 2002;11(4):284-304.

72. Scherzer CB, Brewer BW, Cornelius AE, Van Raalte JL, Petitpas AJ, Sklar JH, et al. Psychological skills and adherence to rehabilitation after reconstruction of the anterior cruciate ligament. Journal of Sport Rehabilitation. 2001;10(3):165-72.

73. Brewer BW, Cornelius AE, Van Raalte JL, Petitpas AJ, Sklar JH, Pohlman MH et al. Age-related differences in predictors of adherence to rehabilitation after anterior cruciate ligament reconstruction. Journal of athletic training. 2003;38(2):158-62.

74. Chan DK, Lonsdale C, Ho PY, Yung PS, Chan KM. Patient motivation and adherence to postsurgery rehabilitation exercise recommendations: the influence of physiotherapists' autonomy-supportive behaviors. Archives of physical medicine and rehabilitation. 2009;90(12):1977-82.

75. Brewer BW, Cornelius AE, Van Raalte JL, Tennen H, Armeli S. Predictors of adherence to home rehabilitation exercises following anterior cruciate ligament reconstruction. Rehabilitation psychology. 2013;58(1):64-72.

76. Hilliard RC, Brewer BW, Cornelius AE, Van Raalte JL. Big five personality characteristics and adherence to clinic-based rehabilitation activities after ACL surgery: a prospective analysis. The open rehabilitation journal. 2014;7:1-5.

77. Brewer BW, Cornelius AE, Van Raalte JL, Petitpas AJ, Sklar JH, Pohlman MH, et al. Attributions for recovery and adherence to rehabilitation following anterior cruciate ligament reconstruction: a prospective analysis. Psychology \& Health. 2000;15(2):283-91.

78. Carson F, Polman RCJ. The facilitative nature of avoidance coping within sports injury rehabilitation. Scandinavian Journal of Medicine \& Science in Sports. 2010;20(2):235-40.

79. Carson F, Polman RCJ. Self-determined motivation in rehabilitating professional rugby union players. BMC Sports Sci Med Rehabil. 2017;9:11.

80. DiSanti J, Lisee C, Erickson K, Bell D, Shingles M, Kuenze C. Perceptions of rehabilitation and return to sport among high school athletes with anterior cruciate ligament reconstruction: a qualitative research study. J Orthop Sports Phys Ther. 2018;48(12):951-9.

81. Dunphy E, Hamilton FL, Spasic I, Button K. Acceptability of a digital health intervention alongside physiotherapy to support patients following anterior cruciate ligament reconstruction. BMC musculoskeletal disorders. 2017;18(1):471.

82. Heijne A, Axelsson K, Werner S, Biguet G. Rehabilitation and recovery after anterior cruciate ligament reconstruction: patients' experiences. Scandinavian journal of medicine \& science in sports. 2008;18(3):325-35.

83. Johnson U, Ivarsson A, Karlsson J, Hagglund M, Walden M, Borjesson M. Rehabilitation after first-time anterior cruciate ligament injury and reconstruction in female football players: a study of resilience factors. BMC sports science, medicine \& rehabilitation. 2016;8:20.

84. Pizzari T, McBurney H, Taylor NF, Feller JA. Adherence to anterior cruciate ligament rehabilitation: a qualitative analysis. Journal of Sport Rehabilitation. 2002;11(2):90-102.

85. Poget F, Blackburn T, Descloux F, Fiddler H. Participating in an exercise group after anterior cruciate ligament reconstruction (ACLR) is perceived to influence psychosocial factors and successful recovery: a focus group qualitative study. Physiotherapy. 2018

86. Sonesson S, Kvist J, Ardern C, Osterberg A, Silbernagel KG. Psychological factors are important to return to pre-injury sport activity after anterior cruciate ligament reconstruction: expect and motivate to satisfy. Knee Surg Sports Traumatol Arthrosc. 2017;25(5):1375-84

87. Greenberg EM, Greenberg ET, Albaugh J, Storey E, Ganley TJ. Rehabilitation practice patterns following anterior cruciate ligament reconstruction: a survey of physical therapists. J Orthop Sports Phys Ther. 2018;48(10):801-11.

88. Culvenor $A G$, Barton CJ. ACL injuries: the secret probably lies in optimising rehabilitation. British journal of sports medicine. 2018;52(22):1416-8.

89. Ebert JR, Webster KE, Edwards PK, Joss BK, D'Alessandro P, Janes G, et al. Current perspectives of Australian therapists on rehabilitation and return to sport after anterior cruciate ligament reconstruction: A survey. Physical therapy in sport : official journal of the Association of Chartered Physiotherapists in Sports Medicine. 2019;35:139-45.

90. Welling W, Benjaminse A, Seil R, Lemmink K, Zaffagnini S, Gokeler A. Low rates of patients meeting return to sport criteria 9 months after anterior cruciate ligament reconstruction: a prospective longitudinal study. Knee Surg Sports Traumatol Arthrosc. 2018;26(12):3636-44.
91. Bailey DL, Holden MA, Foster NE, Quicke JG, Haywood KL, Bishop A. Defining adherence to therapeutic exercise for musculoskeletal pain: a systematic review. British journal of sports medicine. 2020;54(6):326-31.

92. Bollen JC, Dean SG, Siegert RJ, Howe TE, Goodwin VA. A systematic review of measures of self-reported adherence to unsupervised home-based rehabilitation exercise programmes, and their psychometric properties. BMJ open. 2014;4(6):e005044

93. McLean S, Holden MA, Potia T, Gee M, Mallett R, Bhanbhro S, et al. Quality and acceptability of measures of exercise adherence in musculoskeletal settings: a systematic review. Rheumatology. 2017;56(3):426-38.

94. Hall AM, Kamper SJ, Hernon M, Hughes K, Kelly G, Lonsdale C, et al. Measurement tools for adherence to non-pharmacologic self-management treatment for chronic musculoskeletal conditions: a systematic review. Archives of physical medicine and rehabilitation. 2015;96(3):552-62.

95. Frost R, Levati S, McClurg D, Brady M, Williams B. What adherence measures should be used in trials of home-based rehabilitation interventions? A systematic review of the validity, reliability, and acceptability of measures. Archives of physical medicine and rehabilitation. 2017;98(6):1241-56. e45.

96. Ardern CL, Taylor NF, Feller JA, Whitehead TS, Webster KE. Psychological responses matter in returning to preinjury level of sport after anterior cruciate ligament reconstruction surgery. The American journal of sports medicine. 2013:41(7):1549-58.

97. Ardern CL, Kvist J. What is the evidence to support a psychological component to rehabilitation programs after anterior cruciate ligament reconstruction? Current Orthopaedic Practice. 2016;27(3):263-8.

98. Crossman J. Psychological rehabilitation from sports injuries. Sports medicine (Auckland, NZ). 1997;23(5):333-9.

99. Coronado RA, Bird ML, Van Hoy EE, Huston LJ, Spindler KP, Archer KR. Do psychosocial interventions improve rehabilitation outcomes after anterior cruciate ligament reconstruction? A systematic review. Clinical rehabilitation. 2018:32(3):287-98

100. Lynch AD, Logerstedt DS, Grindem H, Eitzen I, Hicks GE, Axe MJ, et al. Consensus criteria for defining 'successful outcome' after $A C L$ injury and reconstruction: a Delaware-Oslo ACL cohort investigation. British journal of sports medicine. 2015:49(5):335-42.

\section{Publisher's Note}

Springer Nature remains neutral with regard to jurisdictional claims in published maps and institutional affiliations.

\section{Submit your manuscript to a SpringerOpen ${ }^{\circ}$ journal and benefit from:}

- Convenient online submission

Rigorous peer review

- Open access: articles freely available online

- High visibility within the field

- Retaining the copyright to your article

Submit your next manuscript at $>$ springeropen.com 